\title{
Application of Supply-Demand-Based Optimization for Parameter Extraction of Solar Photovoltaic Models
}

\author{
Guojiang Xiong $\mathbb{D}^{1},{ }^{1}$ Jing Zhang, ${ }^{1}$ Dongyuan Shi $\mathbb{D}^{2},{ }^{2}$ and Xufeng Yuan ${ }^{1}$ \\ ${ }^{1}$ Guizhou Key Laboratory of Intelligent Technology in Power System, College of Electrical Engineering, Guizhou University, \\ Guiyang 550025, China \\ ${ }^{2}$ State Key Laboratory of Advanced Electromagnetic Engineering and Technology, \\ Huazhong University of Science and Technology, Wuhan 430074, China \\ Correspondence should be addressed to Guojiang Xiong; gjxiongee@foxmail.com
}

Received 12 September 2019; Accepted 30 October 2019; Published 16 November 2019

Guest Editor: Minchul Shin

Copyright () 2019 Guojiang Xiong et al. This is an open access article distributed under the Creative Commons Attribution License, which permits unrestricted use, distribution, and reproduction in any medium, provided the original work is properly cited.

\begin{abstract}
Modeling solar photovoltaic (PV) systems accurately is based on optimal values of unknown model parameters of PV cells and modules. In recent years, the use of metaheuristics for parameter extraction of PV models gains more and more attentions thanks to their efficacy in solving highly nonlinear multimodal optimization problems. This work addresses a novel application of supplydemand-based optimization (SDO) to extract accurate and reliable parameters for PV models. SDO is a very young and efficient metaheuristic inspired by the supply and demand mechanism in economics. Its exploration and exploitation are balanced well by incorporating different dynamic modes of the cobweb model organically. To validate the feasibility and effectiveness of SDO, four PV models with diverse characteristics including RTC France silicon solar cell, PVM 752 GaAs thin film cell, STM6-40/36 monocrystalline module, and STP6-120/36 polycrystalline module are employed. The experimental results comparing with ten state-of-the-art algorithms demonstrate that SDO performs better or highly competitively in terms of accuracy, robustness, and convergence. In addition, the sensitivity of SDO to variation of population size is empirically investigated. The results indicate that SDO with a relatively small population size can extract accurate and reliable parameters for PV models.
\end{abstract}

\section{Introduction}

Rising energy costs, losses in the present-day electricity grid, risks from nuclear power generation, and global environmental changes highlight the increasing significance of renewable energy resources for electricity generation [1]. Among renewable energy resources, solar energy is the most abundant natural resource with many advantages such as easily exploitable, clean, discreet, inexhaustible, long lasting, and reliable $[2,3]$. It has made a leap forward in recent years. According to the International Energy Agency (IEA) [4], renewable energy resources will have the fastest growth in the electricity sector, providing almost $30 \%$ of power demand in 2023, up from $24 \%$ in 2017. During this period, solar photovoltaic (PV) contributes the most with expected $575 \mathrm{GW}$ of new installed capacity. Owing to the ever-growing capacity of $\mathrm{PV}$ in power systems, $\mathrm{PV}$ brings about great changes to power system planning and operating. In such a context, optimal PV models appear especially important to analyze their dynamic conversion behaviors under diverse environmental conditions. Electrical equivalent circuit models are the most popular tools to describe the input-output characteristics of PV cells and modules. Among them, the single diode model (SDM) and the double diode model (DDM) are the most commonly used models [5]. The SDM and DDM have five and seven unknown model parameters, respectively. Extracting accurate values for these unknown parameters is the premise and promise of optimal PV models.

Up to now, a great number of parameter extraction methods for PV models have been elaborated. They can be broken down into two categories from solution principles: analytical methods and optimization methods. The analytical methods are a "taking a part for the whole" methodology. Namely, they mainly rely highly on several key data points 
provided by the manufacturer. These data points such as short-circuit point, open-circuit point, and maximum power point of the current-voltage (I-V) characteristic curve are nameplate rating data measured under standard test condition (STC). They will change over time due to PV degradation [6]. In addition, some assumptions and approximations are introduced to simplify the established mathematical models. In such contexts, the analytical methods will result in inaccuracy in the involved model parameters.

Unlike the analytical methods, the optimization methods are a "taking all actual measured data for the whole" methodology. They are no longer confined to several key data points under the STC provided by the manufacturer but extended to depending on a large number of data points measured under actual operating conditions. These data points cover a wide range of the I-V characteristic curve and thereby can reflect the actual relationship between inputs and outputs of a PV model. The optimization methods firstly construct an objective function to reflect the difference between the measured data and the calculated data based on the idea of curve fitting and then minimize the resultant objective function to obtain values for the unknown model parameters. The optimization methods consist of deterministic methods and metaheuristic methods. The former, including Newton method [7], Newton-Raphson method [8], iterative curve fitting [9], and Levenberg-Marquardt algorithm [10], are considerably dependent on the gradient information and subjected to initial conditions. Therefore, they easily plunge into local minima leading to inaccurate and unreliable solutions especially for complicated multimodal problems such as the parameter extraction problem of PV models.

Different from the deterministic methods, the metaheuristic methods do not need the gradient information. They have no requirements on the specific search domain information or the continuity/convexity of objective functions and exhibit the merits of robustness, simplicity, ease of implementation, etc. [11-13]. Consequently, they are considered global optimization algorithms and have received increasing interests in recent years. The parameter extraction problem of PV models is highly nonlinear, nonconvex, and has many local minima. Under this circumstance, the use of metaheuristic methods for this problem seems to be a promising alternative. Up to now, many metaheuristic methods have been applied to solve this problem. For example, Ismail et al. [14] applied the genetic algorithm (GA) to compute the parameters of both SDM and DDM. Chellaswamy and Ramesh [15] proposed a differential evolution (DE) technique with adaptive mutation factor and crossover rate to different solar cell types. Biswas et al. [16] implemented a linear population size reduction technique of success historybased adaptive DE to estimate parameters for PV models. Jordehi [17] developed a five-staged successive mutation strategy to construct a high-quality leader to pull all particles in particle swarm optimization (PSO) and applied the resultant improved algorithm to three PV models. Merchaoui et al. [18] introduced an adaptive mutation to alleviate the premature convergence of PSO. Askarzadeh and Leandro [19] simplified the original bird mating optimizer (BMO) and used the improved algorithm to an amorphous silicon PV module at different operating conditions. Ali et al. [20] applied multiverse optimization (MVO) to extract five parameters for the SDM. Oliva et al. [21] utilized the chaotic maps to improve the performance of the whale optimization algorithm (WOA) and applied the improved algorithm to different PV models. Chen et al. [22] employed generalized opposition-based learning to enhance teaching-learning-based optimization (TLBO) and applied the modified algorithm to two PV models. Yu et al. [23] obtained parameters for three PV models by an improved JAYA algorithm with three strategies including self-adaptive weight, experience-based learning strategy, and chaotic elite learning method. Xiong et al. solved the parameter extraction problem of different PV models by using several metaheuristics including symbiotic organisms search (SOS) algorithm [24], improved WOA based on two modified prey searching strategies [25], and hybrid DE with WOA [26]. In addition to the aforementioned metaheuristics, many more [27-40] have also been presented to solve the important problem.

The abovementioned metaheuristics have, to some extent, proven themselves promising methods for the parameter extraction problem of $\mathrm{PV}$ models. Their performances are largely attributed to their own well-tuned parameters and well-designed search strategies for balancing the exploration and exploitation. According to the famous no-free-launch theorem [41], there is no "one size fits all" approach for solving all optimization problems. Similarly, there is no "one size fits all" metaheuristic for extracting accurate parameters for all PV models, which highly motivates the authors to attempt new ones for the purpose of achieving optimal or suboptimal solutions for the problem considered here.

In this paper, a very young and effective metaheuristic named supply-demand-based optimization (SDO) [42] developed in 2019 is first applied to the parameter extraction problem of PV models. SDO mathematically mimics both the demand relation of consumers and supply relation of producers described by the famous cobweb theory in economics. According to the cobweb model $[43,44]$, markets have three dynamic modes, i.e., convergent mode, divergent mode, and closed mode. They correspond to the exploitation, exploration, and demarcation between them in SDO, respectively. SDO can incorporate these three modes organically. It has shown high competition in solving some benchmark test functions and mechanical engineering optimization problems compared with some popular metaheuristics such as PSO, DE, GA, and TLBO. In this paper, the SDO is applied to four PV models with diverse characteristics, i.e., the RTC France silicon solar cell, PVM 752 GaAs thin film cell, STM6-40/36 monocrystalline module, and STP6-120/36 polycrystalline module. Ten state-of-the-art metaheuristics are employed to verify the feasibility and effectiveness of SDO. Besides, the sensitivity of SDO to variation of population size is also empirically investigated.

The rest of this paper is organized as follows. Section 2 describes the mathematical formulation of parameter extraction problem of PV models. Section 3 introduces the supply and demand mechanism of the cobweb model. The SDO is detailed in Section 4. Section 5 presents the experimental results and comparisons. Finally, the paper is concluded in Section 6. 


\section{Problem Formulation}

2.1. Single Diode Model (SDM). The output current $I_{\mathrm{L}}$ of the SDM shown in Figure 1 is calculated as follows:

$$
I_{\mathrm{L}}=I_{\mathrm{ph}}-I_{\mathrm{d}}-I_{\mathrm{sh}},
$$

where $I_{\mathrm{ph}}, I_{\mathrm{sh}}$, and $I_{\mathrm{d}}$ denote the photogenerated current, shunt resistor current, and diode current, respectively. $I_{\mathrm{d}}$ and $I_{\text {sh }}$ are formulated as follows [5, 45-47]:

$$
\begin{aligned}
& I_{\mathrm{d}}=I_{\mathrm{sd}} \cdot\left[\exp \left(\frac{V_{\mathrm{L}}+R_{\mathrm{s}} \cdot I_{\mathrm{L}}}{n V_{\mathrm{t}}}\right)-1\right], \\
& V_{\mathrm{t}}=\frac{k T}{q} \\
& I_{\mathrm{sh}}=\frac{V_{\mathrm{L}}+R_{\mathrm{s}} \cdot I_{\mathrm{L}}}{R_{\mathrm{sh}}}
\end{aligned}
$$

where $I_{\text {sd }}$ is the saturation current, $V_{\mathrm{L}}$ is the output voltage, $R_{\mathrm{s}}$ and $R_{\mathrm{sh}}$ are the series resistance and shunt resistance, respectively, $n$ is the diode ideal factor, $k$ is the Boltzmann constant $\left(1.3806503 \times 10^{-23} \mathrm{~J} / \mathrm{K}\right), q$ is the electron charge $\left(1.60217646 \times 10^{-19} \mathrm{C}\right)$, and $T$ is the cell temperature $(\mathrm{K})$.

By incorporating equations (2)-(4) into (1), the output current $I_{\mathrm{L}}$ can be yielded as follows:

$$
I_{\mathrm{L}}=I_{\mathrm{ph}}-I_{\mathrm{sd}} \cdot\left[\exp \left(\frac{V_{\mathrm{L}}+R_{\mathrm{s}} \cdot I_{\mathrm{L}}}{n V_{\mathrm{t}}}\right)-1\right]-\frac{V_{\mathrm{L}}+R_{\mathrm{s}} \cdot I_{\mathrm{L}}}{R_{\mathrm{sh}}} .
$$

It is obvious that the SDM has five unknown parameters (i.e., $I_{\mathrm{ph}}, I_{\mathrm{sd}}, R_{\mathrm{s}}, R_{\mathrm{sh}}$, and $n$ ) that need to be extracted.

2.2. Double Diode Model (DDM). The DDM considers the effect of recombination current loss in the depletion region and therefore performs well in some applications especially for thin films at low irradiance [46]. The output current $I_{\mathrm{L}}$ of the DDM in Figure 2 is formulated as follows $[5,46]$ :

$$
\begin{aligned}
I_{\mathrm{L}}= & I_{\mathrm{ph}}-I_{\mathrm{d} 1}-I_{\mathrm{d} 2}-I_{\mathrm{sh}} \\
= & I_{\mathrm{ph}}-I_{\mathrm{sd} 1} \cdot\left[\exp \left(\frac{V_{\mathrm{L}}+R_{\mathrm{s}} \cdot I_{\mathrm{L}}}{n_{1} V_{\mathrm{t}}}\right)-1\right]-I_{\mathrm{sd} 2} \\
& \cdot\left[\exp \left(\frac{V_{\mathrm{L}}+R_{\mathrm{s}} \cdot I_{\mathrm{L}}}{n_{2} V_{\mathrm{t}}}\right)-1\right]-\frac{V_{\mathrm{L}}+R_{\mathrm{s}} \cdot I_{\mathrm{L}}}{R_{\mathrm{sh}}}
\end{aligned}
$$

where $I_{\mathrm{sd} 1}$ and $I_{\mathrm{sd} 2}$ are diode currents and $n_{1}$ and $n_{2}$ are diode ideal factors. The DDM has seven unknown parameters (i.e., $I_{\mathrm{ph}}, I_{\mathrm{sd} 1}, I_{\mathrm{sd} 2}, R_{\mathrm{s}}, R_{\mathrm{sh}}, n_{1}$, and $n_{2}$ ) that need to be extracted.

2.3. PV Module Model. The output current $I_{\mathrm{L}}$ of a $\mathrm{PV}$ module with $N_{s} \times N_{p}$ solar cells in series and/or in parallel can be calculated as follows.

For the SDM-based PV module,

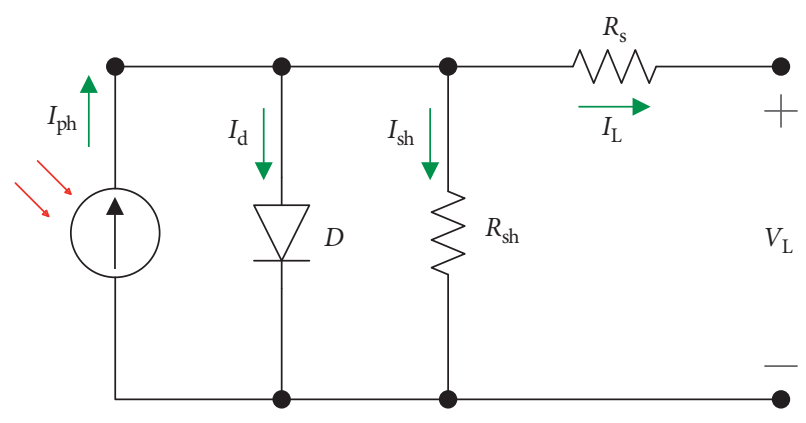

FIgURE 1: Equivalent circuit of the SDM.

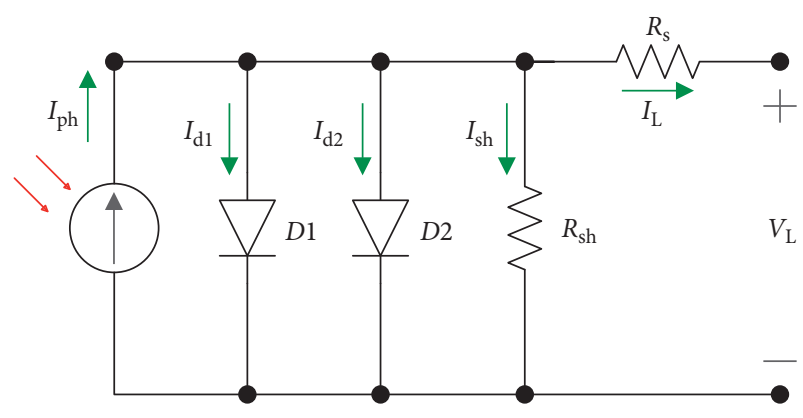

Figure 2: Equivalent circuit of the DDM.

$$
\begin{aligned}
I_{\mathrm{L}}= & N_{\mathrm{p}}\left\{I_{\mathrm{ph}}-I_{\mathrm{sd}} \cdot\left[\exp \left(\frac{V_{\mathrm{L}} / N_{\mathrm{s}}+R_{\mathrm{s}} I_{\mathrm{L}} / N_{\mathrm{p}}}{n V_{\mathrm{t}}}\right)-1\right]\right. \\
& \left.-\frac{V_{\mathrm{L}} / N_{\mathrm{s}}+R_{\mathrm{s}} I_{\mathrm{L}} / N_{\mathrm{p}}}{R_{\mathrm{sh}}}\right\} .
\end{aligned}
$$

For the DDM-based PV module,

$$
\begin{aligned}
I_{\mathrm{L}}= & N_{\mathrm{p}}\left\{I_{\mathrm{ph}}-I_{\mathrm{sd} 1} \cdot\left[\exp \left(\frac{V_{\mathrm{L}} / N_{\mathrm{s}}+R_{\mathrm{s}} I_{\mathrm{L}} / N_{\mathrm{p}}}{n_{1} V_{\mathrm{t}}}\right)-1\right]\right. \\
& \left.-I_{\mathrm{sd} 2} \cdot\left[\exp \left(\frac{V_{\mathrm{L}} / N_{\mathrm{s}}+R_{\mathrm{s}} I_{\mathrm{L}} / N_{\mathrm{p}}}{n_{2} V_{\mathrm{t}}}\right)-1\right]-\frac{V_{\mathrm{L}} / N_{\mathrm{s}}+R_{\mathrm{s}} I_{\mathrm{L}} / N_{\mathrm{p}}}{R_{\mathrm{sh}}}\right\} .
\end{aligned}
$$

2.4. Objective Function. In general, the root mean square error (RMSE) between the measured current $I_{L \text {,measured }}$ and the calculated current $I_{L \text {,calculated }}$ is used as the objective function $[15,17-19,21-23]$ :

$$
\min f(\mathbf{x})=\operatorname{RMSE}(\mathbf{x})=\sqrt{\frac{1}{N} \sum_{k=1}^{N}\left[I_{L, \text { calculated }}^{k}(\mathbf{x})-I_{L, \text { measured }}^{k}\right]^{2}}
$$

where $N$ is the number of measured data and $\mathbf{x}$ is the vector of unknown parameters.

\section{Supply and Demand Mechanism of the Cobweb Model}

The cobweb model $[43,44]$ is a famous economic theory used to study the fluctuation relationship between the price 
and quantity of a commodity in a perfectly competitive market. It was apparently first named by Nicholas Kardor in 1934. The cobweb model is a dynamic equilibrium analysis theory based on elastic principle. According to this theory, for a given commodity, its quantity $Q_{t+1}$ in the next time reacts to its current price $P_{t}$ with an increasing supply function $Q_{t+1}=g\left(P_{t}\right)$ due to production lags, while its price $P_{t+1}$ in the next time depends only on its corresponding quantity $Q_{t+1}$ at the same time with a decreasing demand function $P_{t}=f\left(Q_{t}\right)$. Generally, both functions $f(\cdot)$ and $g(\cdot)$ are assumed to be linear as follows for the sake of simplification:

$$
\begin{gathered}
\text { Supply function } g(\cdot): Q_{t+1}-Q_{e}=K_{g}\left(P_{t}-P_{e}\right) \text {, } \\
\text { Demand function } f(\cdot): P_{t+1}-P_{e}=K_{f}\left(Q_{t+1}-Q_{e}\right),
\end{gathered}
$$

where $K_{g}>0$ and $K_{f}<0$ are the supply slop and demand slop, respectively, and $E_{e}\left(Q_{e}, P_{e}\right)^{\mathrm{T}}$ is an equilibrium point.

By substituting equation (10) into equation (11), the following formulation is yielded:

$$
P_{t+1}=K_{f} K_{g} P_{t}+\left(1-K_{f} K_{g}\right) P_{e} .
$$

Consequently, we can obtain the following equation (13) easily by using recursion:

$$
P_{t+1}=\left(K_{f} K_{g}\right)^{t} P_{1}+\left(1-\left(K_{f} K_{g}\right)^{t}\right) P_{e} .
$$

It can be seen from (13) that markets have the following three dynamic modes:

(i) Convergent mode: If $\left|K_{f} K_{g}\right|<1$, then $\lim _{t \rightarrow \infty} P_{t} \longrightarrow P_{e}$; therefore, this market is stable and the price and quantity tend to spiral inwards with time as shown in Figure 3(a).

(ii) Divergent mode: If $\left|K_{f} K_{g}\right|>1$, then $\lim _{t \rightarrow \infty} P_{t} \longrightarrow \infty$, which means that this market is divergent and the price and quantity tend to spiral outwards with time as shown in Figure 3(b).

(iii) Closed mode: If $\left|K_{f} K_{g}\right|=1$, when the time $t$ is even, $\lim _{t \rightarrow \infty} P_{t}=P_{1}$; when $t$ is odd, $\lim _{t \rightarrow \infty} P_{t}=2 P_{e}-P_{1}$. Hence, this market is oscillating and the price has the same impact on the supply and demand of the market as shown in Figure 3(c).

\section{Supply-Demand-Based Optimization (SDO)}

SDO [42] is a very young and effective metaheuristic algorithm inspired by the cobweb theory about the supply and demand mechanism. In SDO, there are ps markets and each market is considered a solution for a given optimization problem. Each market has $D$ commodities corresponding to variables of the problem. Each commodity has a certain price and quantity at a given time. Therefore, each market actually has two solutions where one is a candidate solution $\mathbf{P}_{i}^{t}=$ $\left[P_{i, 1}^{t}, P_{i, 2}^{t}, \ldots, P_{i, D}^{t}\right]$ represented by the prices of commodities and the other is a possible solution $\mathbf{Q}_{i}^{t}=\left[Q_{i, 1}^{t}, Q_{i, 2}^{t}, \ldots, Q_{i, D}^{t}\right]$ composed by the quantities of commodities, where $i=1,2, \ldots, \mathrm{ps}, t=1,2, \ldots, t_{\max }, t_{\max }$ is the maximum number of iterations. Each price solution $\mathbf{P}_{i}^{t}$ and quantity solution $\mathbf{Q}_{i}^{t}$ are associated with the fitness values $f\left(\mathbf{P}_{i}^{t}\right)$ and $f\left(\mathbf{Q}_{i}^{t}\right)$, respectively. The fitness value $f\left(\mathbf{P}_{i}^{t}\right)$ is directly analogous to the rationality of a market. The price solution $\mathbf{P}_{i}^{t}$ will be replaced by the quantity solution $\mathbf{Q}_{i}^{t}$ if $\mathbf{Q}_{i}^{t}$ is more rational, i.e., $f\left(\mathbf{Q}_{i}^{t}\right)$ is smaller than $f\left(\mathbf{P}_{i}^{t}\right)$ for a minimization optimization problem.

Although both the price solution $\mathbf{P}_{i}^{t}$ and quantity solution $\mathbf{Q}_{i}^{t}$ serve as solutions, they have different updating strategies. It can be seen from equations (10) and (11) that the prerequisite of obtaining the prices and quantities of a market is getting the position of the equilibrium point $\mathbf{E}_{e}^{t}=\left[E_{e, 1}^{t}, E_{e, 2}^{t}, \ldots, E_{e, D}^{t}\right]=\left[\begin{array}{c}Q_{e, 1}^{t}, Q_{e, 2}^{t}, \ldots, Q_{e, D}^{t} \\ P_{e, 1}^{t}, P_{e, 2}^{t}, \ldots, P_{e, D}^{t}\end{array}\right] . \quad$ How ever, the equilibrium point is not known a priori during the iterations. In this context, SDO adopts the following methods to determine the equilibrium point $\mathbf{E}_{e}^{t}$ at each iteration. For the quantity, each market chooses a quantity solution $\mathbf{Q}_{k}^{t}=\left[Q_{k, 1}^{t}, Q_{k, 2}^{t}, \ldots, Q_{k, D}^{t}\right]$ probabilistically as its quantity equilibrium vector $\mathbf{Q}_{e}^{t}=\left[Q_{e, 1}^{t}, Q_{e, 2}^{t}, \ldots, Q_{e, D}^{t}\right]$ using fitness value-based roulette wheel selection as follows:

$$
\begin{aligned}
\lambda_{i} & =\left|f\left(\mathbf{Q}_{i}^{t}\right)-\frac{1}{\mathrm{ps}} \sum_{i=1}^{\mathrm{ps}} f\left(\mathbf{Q}_{i}^{t}\right)\right|, \\
\mu_{i} & =\frac{\lambda_{i}}{\sum_{i=1}^{\mathrm{ps}} \lambda_{i}}, \\
\mathbf{Q}_{e}^{t} & =\mathbf{Q}_{k}^{t}, \quad k=\text { Roulette Wheel Selection }(\boldsymbol{\mu}),
\end{aligned}
$$

where $\boldsymbol{\mu}=\left[\mu_{1}, \mu_{2}, \ldots, \mu_{\mathrm{ps}}\right]$.

Concerning the price, each market chooses either a price solution $\mathbf{P}_{k}^{t}=\left[P_{k, 1}^{t}, P_{k, 2}^{t}, \ldots, P_{k, D}^{t}\right]$ probabilistically using fitness value-based roulette wheel selection or the average price vector $\overline{\mathbf{P}^{t}}=\left[\overline{P_{1}^{t}}, \overline{P_{2}^{t}}, \ldots, \overline{P_{D}^{t}}\right]$ of all markets as its quantity equilibrium vector $\mathbf{P}_{e}^{t}=\left[P_{e, 1}^{t}, P_{e, 2}^{t}, \ldots, P_{e, D}^{t}\right] . \mathbf{P}_{k}^{t}$ and $\overline{\mathbf{P}^{t}}$ are chosen with the same probability:

$$
\begin{aligned}
\rho_{i} & =\left|f\left(\mathbf{P}_{i}^{t}\right)-\frac{1}{\mathrm{ps}} \sum_{i=1}^{\mathrm{ps}} f\left(\mathbf{P}_{i}^{t}\right)\right|, \\
\sigma_{i} & =\frac{\rho_{i}}{\sum_{i=1}^{\mathrm{ps}} \rho_{i}}, \\
\mathbf{P}_{e}^{t} & = \begin{cases}r_{1} \cdot \mathbf{P}_{k}^{t}, & \text { if } r_{2} \geq 0.5, \\
\overline{\mathbf{P}^{t}}, & \text { if } r_{2}<0.5,\end{cases}
\end{aligned}
$$

where $\overline{P_{d}^{t}}=(1 / \mathrm{ps}) \sum_{i=1}^{\mathrm{ps}} P_{i, d}^{t}, \quad d=1,2, \ldots, D, \quad k=$ Roulette Wheel Selection Wheel Selection $(\boldsymbol{\sigma}), \boldsymbol{\sigma}=\left[\sigma_{1}, \sigma_{2}, \ldots, \sigma_{\mathrm{ps}}\right]$, and $r_{1}$ and $r_{2}$ are random real numbers in $(0,1)$.

After getting the position of the equilibrium point $\mathbf{E}_{e}^{t}=\left[E_{e, 1}^{t}, E_{e, 2}^{t}, \ldots, E_{e, D}^{t}\right]$, the quantity and price adopt the following strategies to generate their corresponding trial vectors $\mathbf{T Q}_{k}^{t}=\left[T Q_{i, 1}^{t}, T Q_{i, 2}^{t}, \ldots, T Q_{i, D}^{t}\right]$ and $\mathbf{T P}_{k}^{t}=\left[T P_{i, 1}^{t}\right.$, $\left.T P_{i, 2}^{t}, \ldots, T P_{i, D}^{t}\right]$, respectively: 


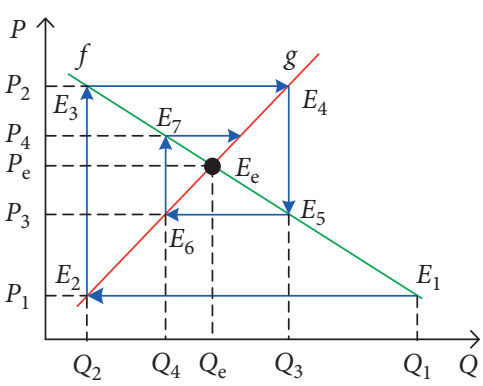

(a)

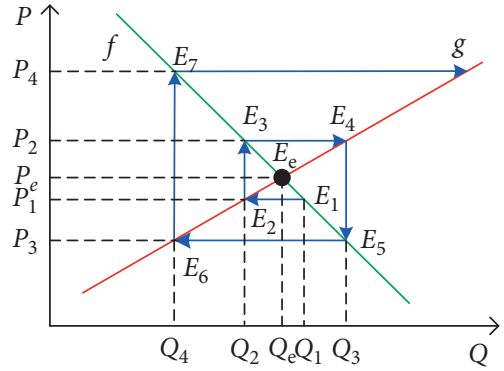

(b)

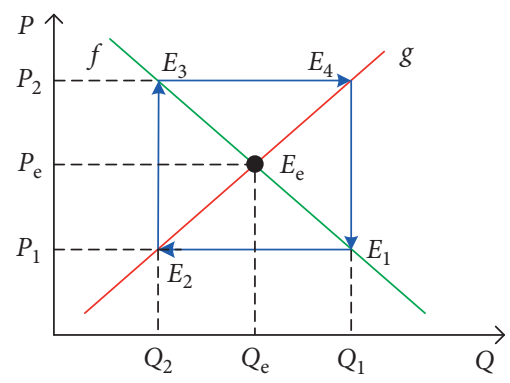

(c)

Figure 3: Dynamic modes of the cobweb model. (a) Convergent mode; (b) divergent mode; (c) closed mode.

$$
\begin{aligned}
& T Q_{i, d}^{t}=Q_{e, d}^{t}+\alpha \cdot\left(P_{i, d}^{t}-P_{e, d}^{t}\right), \\
& T P_{i, d}^{t}=P_{e, d}^{t}+\beta \cdot\left(T Q_{i, d}^{t}-Q_{e, d}^{t}\right),
\end{aligned}
$$

where $d=1,2, \ldots, D$, and $\alpha$ and $\beta$ denote the supply weight and demand weight, respectively. They are determined as follows:

$$
\begin{aligned}
& \alpha=\frac{2 \cdot\left(t_{\max }-t+1\right)}{t_{\max }} \cdot \sin \left(2 \pi r_{3}\right), \\
& \beta=2 \cdot \cos \left(2 \pi r_{4}\right),
\end{aligned}
$$

where $r_{3}$ and $r_{4}$ are random real numbers in $(0,1)$.

Thereafter, a selection is implemented to choose a fitter one as follows:

$$
\begin{aligned}
& \mathbf{Q}_{i}^{t+1}= \begin{cases}\mathbf{T} \mathbf{Q}_{i}^{t}, & \text { if } f\left(\mathbf{T} \mathbf{Q}_{i}^{t}\right) \leq f\left(\mathbf{Q}_{i}^{t}\right), \\
\mathbf{Q}_{i}^{t}, & \text { otherwise, }\end{cases} \\
& \mathbf{P}_{i}^{t+1}= \begin{cases}\mathbf{T} \mathbf{P}_{i}^{t}, & \text { if } f\left(\mathbf{T P}_{i}^{t}\right) \text { is the smallest one, } \\
\mathbf{Q}_{i}^{t+1}, & \text { if } f\left(\mathbf{Q}_{i}^{t+1}\right) \text { is the smallest one, } \\
\mathbf{P}_{i}^{t}, & \text { otherwise. }\end{cases}
\end{aligned}
$$

It can be seen that if $|\alpha \beta|<1$, then the corresponding market is stable or convergent, which means the supply and demand mechanism defines a search space in the neighborhood of the equilibrium point and allows the market to exploit its prices inside that domain. If $|\alpha \beta|>1$, the corresponding market is divergent, indicating that the supply and demand mechanism defines a large search space far away from the equilibrium point and allows the market to explore its prices in new promising areas. $|\alpha \beta|=1$ corresponds to the critical point between the exploration and exploitation. In addition, equations (17) and (18) enable SDO a smooth transition from exploration to exploitation as the iterations progress. Therefore, SDO exhibits exploration and exploitation and possesses an ability to balance them. The flowchart of SDO is shown in Figure 4.

\section{Experimental Results}

To validate the performance of SDO in solving the parameter extraction problem of PV models, SDO is applied to the following four different PV models with diverse characteristics: (i) RTC France silicon solar cell [48]: contains 26 pairs of $\mathrm{I}-\mathrm{V}$ data points measured at $33^{\circ} \mathrm{C}$ under $1000 \mathrm{~W} / \mathrm{m}^{2}$ irradiance

(ii) PVM 752 GaAs thin film cell [17]: contains 44 pairs of $\mathrm{I}-\mathrm{V}$ data points measured at $25^{\circ} \mathrm{C}$ under $1000 \mathrm{~W} / \mathrm{m}^{2}$ irradiance

(iii) STM6-40/36 monocrystalline module $[30,49]$ : composed of 36 cells in series with 20 pairs of I-V data points measured at $51^{\circ} \mathrm{C}$

(iv) STP6-120/36 polycrystalline module $[30,49]$ : composed of 36 cells in series with 24 pairs of I-V data points measured at $55^{\circ} \mathrm{C}$

The search ranges for the involved parameters are presented in Table 1. In this work, both the SDM and DDM are used to model all of these four PV models. In addition, ten state-of-the-art algorithms including comprehensive learning particle swarm optimizer (CLPSO) [50], hybrid differential evolution with biogeography-based optimization (DE/BBO) [51], generalized oppositional teaching-learningbased optimization (GOTLBO) [22], improved JAYA optimization algorithm (IJAYA) [23], improved whale optimization algorithm (IWOA) [25], teaching-learning-based optimization with learning experience of other learners (LETLBO) [52], modified artificial bee colony algorithm (MABC) [53], opposition-based differential evolution (ODE) [54], teaching-learning-based artificial bee colony (TLABC) [55], and self-adaptive teaching-learning-based optimization (SATLBO) [56] are employed to verify SDO. The parameter settings for these ten compared algorithms are kept the same as those in their original literature and summarized in Table 2. The maximum number of fitness evaluations (Max_FEs) setting as $50000[23,24,26,30,55,56]$ serves as the stopping condition for fair comparison. In addition, for each algorithm, 50 independent runs are executed in MATLAB 2017a.

5.1. Results on the RTC France Silicon Solar Cell. The experimental results including the minimum (Min), maximum (Max), mean (Mean), and standard deviation (Std Dev) values of the RMSE values over 50 independent runs are recorded. Because the actual values for the involved parameters are not known a priori, so the RMSE values can be used as an index to weigh the extraction accuracy. 


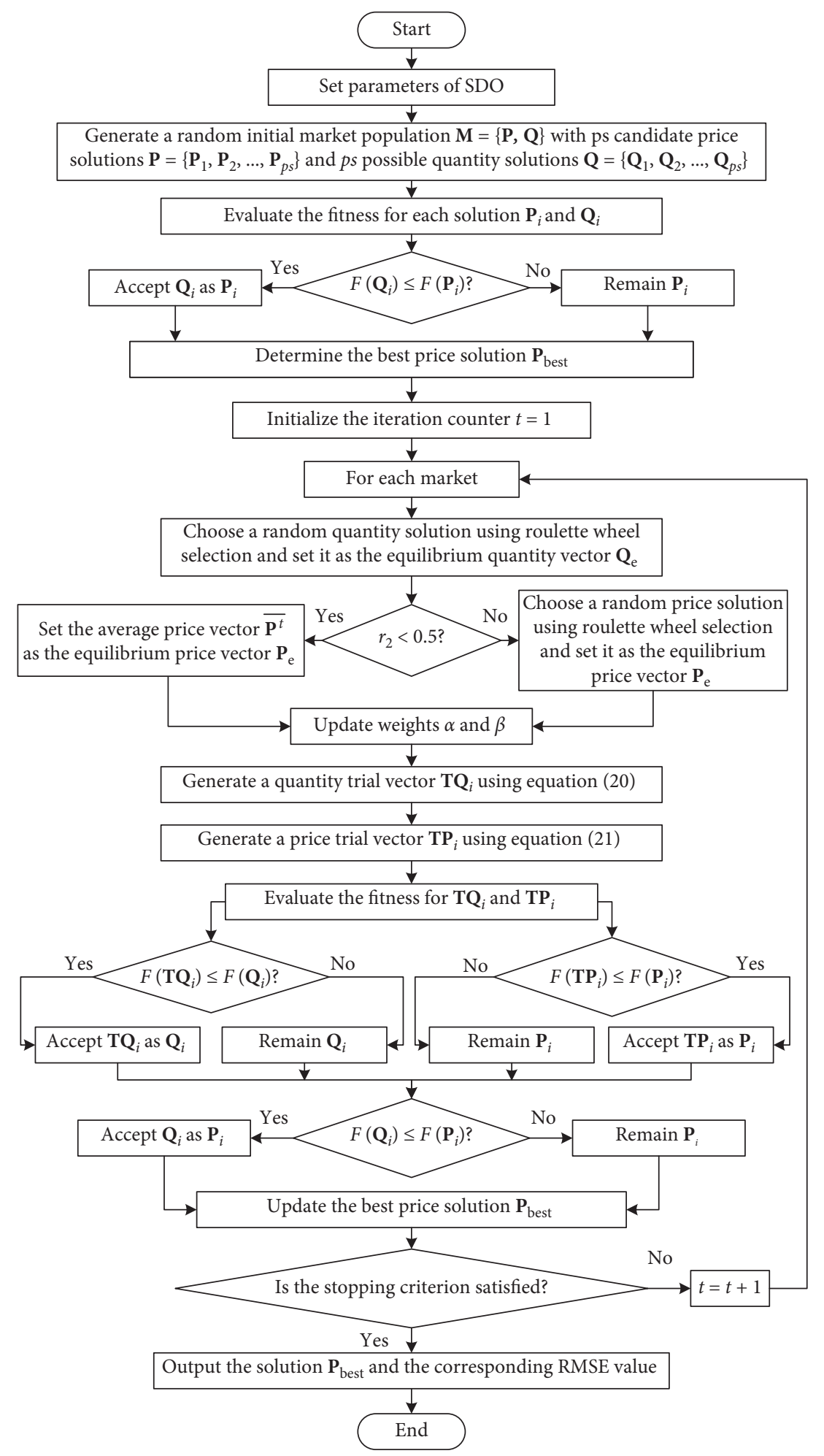

FIgUre 4: The flowchart of SDO.

For the RTC France silicon solar cell, the experimental results are summarized in Table 3 . The best results are highlighted in boldface. It can be seen that, for the SDM, five algorithms including SDO, DE/BBO, ODE, SATLBO, and TLABC achieve the smallest RMSE value $(9.8602 E-04)$. Even so, SDO gets better results in terms of the maximum
RMSE, mean RMSE, and standard deviation values, indicating that it is more robust and can obtain more reliable and accurate values for the unknown parameters. For the DDM, SDO performs the best in all terms of RMSE values, demonstrating its robustness and accuracy again. In addition, Wilcoxon's rank sum test at confidence level 0.05 is 
TABLE 1: Search ranges of parameters of PV models.

\begin{tabular}{lccccccc}
\hline & \multicolumn{2}{c}{ RTC France cell } & \multicolumn{2}{c}{ PVM 752 GaAs cell } & \multicolumn{2}{c}{$\begin{array}{c}\text { STM6-40/36 } \\
\text { module }\end{array}$} & \multicolumn{2}{c}{$\begin{array}{c}\text { STP6-120/36 } \\
\text { module }\end{array}$} \\
& PB & UB & LB & UB & LB & UB & LB \\
\hline$I_{\mathrm{ph}}(\mathrm{A})$ & 0 & 1 & 0 & 1 & 0 & 2 & 0 \\
$I_{\mathrm{sd}}(\mu \mathrm{A})$ & 0 & 1 & 0 & 1 & 0 & 50 & 0 \\
$R_{\mathrm{s}}(\Omega)$ & 0 & 0.5 & 0 & 1 & 0 & 0.36 & 0 \\
$R_{\mathrm{sh}}(\Omega)$ & 0 & 100 & 0 & 1000 & 0 & 1000 & 0 \\
$n, n_{1}, n_{2}$ & 1 & 2 & 1 & 2 & 1 & 60 & 1500 \\
\hline
\end{tabular}

TABle 2: Parameter settings for involved algorithms.

\begin{tabular}{lc}
\hline Algorithm & Parameter settings \\
\hline CLPSO & $\mathrm{ps}=40, w=0.9 \longrightarrow 0.4, c=1.49445, m=7$ \\
DE/BBO & $\mathrm{ps}=100, F=\mathrm{rand}(0.1,0.9), \mathrm{CR}=0.9, E=I=1$ \\
GOTLBO & $\mathrm{ps}=50, \mathrm{Jr}=0.4$ \\
IJAYA & $\mathrm{ps}=20$ \\
IWOA & $\mathrm{ps}=50, a=2 \longrightarrow 0$ \\
LETLBO & $\mathrm{ps}=50 \quad \mathrm{ps}=150$, limit $=100, P=0.7$ \\
MABC & $\mathrm{ps}=100, F=0.5, \mathrm{CR}=0.9, \mathrm{Jr}=0.3$ \\
ODE & $\mathrm{ps}=40$ \\
SATLBO & $\mathrm{ps}=50$, limit $=200, F=\mathrm{rand}(0,1)$ \\
TLABC & $\mathrm{ps}=20$ \\
SDO & \\
\hline
\end{tabular}

TABLE 3: Experimental results on the RTC France solar cell.

\begin{tabular}{|c|c|c|c|c|c|c|}
\hline Model & Algorithm & Min & Max & Mean & Std. dev. & Significance \\
\hline \multirow{11}{*}{ SDM } & CLPSO & $1.0016 E-03$ & $1.4520 E-03$ & $1.1329 E-03$ & $1.0917 E-04$ & $\dagger$ \\
\hline & $\mathrm{DE} / \mathrm{BBO}$ & $9.8602 E-04$ & $1.2373 E-03$ & $1.0533 E-03$ & $5.0412 E-05$ & $\dagger$ \\
\hline & GOTLBO & $9.8627 E-04$ & $1.4071 E-03$ & $1.0796 E-03$ & $9.8773 E-05$ & $\dagger$ \\
\hline & IJAYA & $9.8603 E-04$ & $1.0019 E-03$ & $9.8934 E-04$ & $3.5283 E-06$ & $\dagger$ \\
\hline & IWOA & $9.8829 E-04$ & $3.2095 E-03$ & $1.4633 E-03$ & $3.7745 E-04$ & $\dagger$ \\
\hline & LETLBO & $9.8604 E-04$ & $1.1558 E-03$ & $1.0145 E-03$ & $3.7825 E-05$ & $\dagger$ \\
\hline & MABC & $1.0154 E-03$ & $1.8145 E-03$ & $1.1980 E-03$ & $1.6722 E-04$ & $\dagger$ \\
\hline & ODE & $9.8602 \mathrm{E}-04$ & $1.4627 E-03$ & $1.0628 E-03$ & $1.1279 E-04$ & $\dagger$ \\
\hline & SATLBO & $9.8602 \mathrm{E}-04$ & $1.0416 E-03$ & $9.9082 E-04$ & $9.3056 E-06$ & $\dagger$ \\
\hline & TLABC & $9.8602 \mathrm{E}-04$ & $1.0311 E-03$ & $9.9051 E-04$ & $9.3740 E-06$ & $\dagger$ \\
\hline & SDO & $9.8602 \mathrm{E}-04$ & $9.8616 \mathrm{E}-04$ & $9.8603 \mathrm{E}-04$ & $2.5141 \mathrm{E}-08$ & \\
\hline \multirow{11}{*}{ DDM } & CLPSO & $1.0084 E-03$ & $1.7444 E-03$ & $1.2000 E-03$ & $1.4938 E-04$ & $\dagger$ \\
\hline & $\mathrm{DE} / \mathrm{BBO}$ & $9.8589 E-04$ & $1.7089 E-03$ & $1.1715 E-03$ & $1.8756 E-04$ & $\dagger$ \\
\hline & GOTLBO & $9.8736 E-04$ & $1.4216 E-03$ & $1.1419 E-03$ & $1.2637 E-04$ & $\dagger$ \\
\hline & IJAYA & $9.8439 E-04$ & $1.1977 E-03$ & $1.0045 E-03$ & $3.6754 E-05$ & $\dagger$ \\
\hline & IWOA & $9.8629 E-04$ & $2.1982 E-03$ & $1.3907 E-03$ & $3.0524 E-04$ & $\dagger$ \\
\hline & LETLBO & $9.8270 E-04$ & $1.3936 E-03$ & $1.0648 E-03$ & $1.0259 E-04$ & $\dagger$ \\
\hline & MABC & $9.8707 E-04$ & $1.2597 E-03$ & $1.0740 E-03$ & $5.8610 E-05$ & $\dagger$ \\
\hline & ODE & $9.8271 E-04$ & $1.1779 E-03$ & $9.9590 E-04$ & $3.1806 E-05$ & $\approx$ \\
\hline & SATLBO & $9.8301 E-04$ & $1.1634 E-03$ & $1.0024 E-03$ & $3.5296 E-05$ & $\dagger$ \\
\hline & TLABC & $9.8349 E-04$ & $1.2529 E-03$ & $1.0247 E-03$ & $6.0243 E-05$ & $\dagger$ \\
\hline & SDO & $9.8250 \mathrm{E}-04$ & $1.0271 \mathrm{E}-03$ & $9.8822 \mathrm{E}-04$ & $8.8518 E-06$ & \\
\hline
\end{tabular}

used to compare the significance between SDO and other

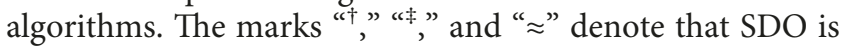
better than, worse than, and similar to the compared algorithm, respectively. It is clear that SDO is significantly better than all of the other ten compared algorithms on the SDM. With regards to the DDM, SDO wins other nine algorithms except ODE while both SDO and ODE get the similar results statistically. Moreover, the convergence curves illustrated in Figure 5 are provided to study the convergence property of SDO. It shows that IJAYA converges the fastest at the large part of evolutionary process. Nevertheless, it is gradually overtaken and finally surpassed by SDO after about 35000 and 34000 fitness evaluations for the SDM and DDM, respectively, indicating that SDO has a 


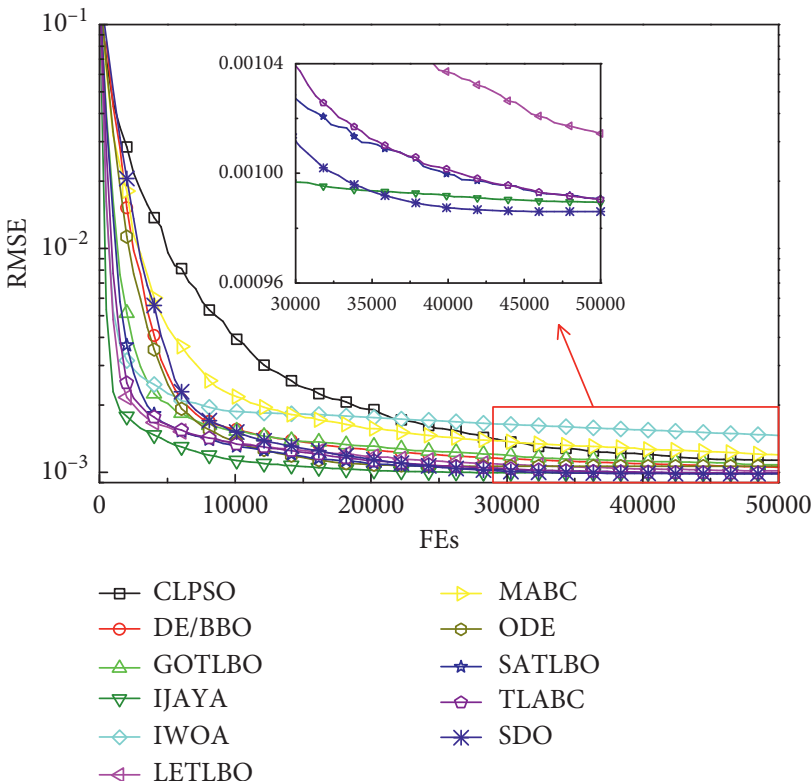

(a)

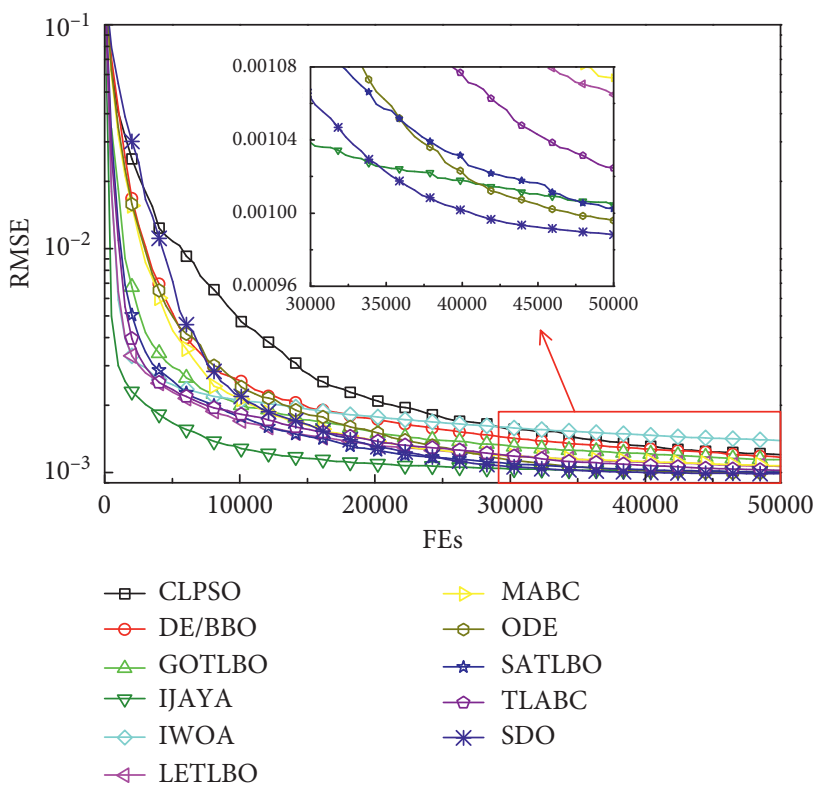

(b)

FIgURe 5: Convergence curves for the RTC France silicon solar cell. (a) SDM; (b) DDM.

relatively fast convergence speed throughout the evolutionary process.

The extracted values obtained by SDO for the involved unknown parameters corresponding to the minimum RMSE are listed in Table 4. With these extracted parameters, the I-V and $\mathrm{P}-\mathrm{V}$ characteristic curves can be reconstructed easily as shown in Figure 6. It is obvious that the calculated data achieved by SDO agree with the measured data well throughout the entire voltage range. In addition, the individual absolute error (IAE) between the calculated current and measured current is recorded in Table 5. All of the IAE values are smaller than 0.0016 , meaning that the values extracted by SDO for the involved parameters of both the SDM and DDM are very accurate.

Additionally, comparing the results of the SDM and DDM, we can find that the minimum RMSE value provided by the DDM is lower than that given by the SDM. The sum of IAE obtained by the DDM is 0.01730620 which is smaller than that $(0.1770381)$ given by SDM, indicating that the DDM may be more suitable for the RTC France silicon solar cell. On the other side, we also observe that the SDM is better than the DDM in terms of the maximum RMSE, mean RMSE, and standard deviation values. This is mainly because the DDM has seven unknown parameters that need to be extracted while the SDM only has five. Therefore, the DDM is more complex with more local minima and the solution algorithms are more likely to get into them.

5.2. Results on PVM 752 GaAs Thin Film Cell. For the PVM 752 GaAs thin film cell, the RMSE values are presented in Table 6. It is clear that IJAYA achieves the best values in all terms of RMSE for the SDM while SDO gets the second best minimum RMSE value. Considering the maximum RMSE and mean RMSE, besides IJAYA, both SATLBO and TLABC are also better than SDO while SDO performs better than the rest seven algorithms, which is also verified by Wilcoxon's rank sum test results. For the DDM, IJAYA still performs well but it is worse than SDO in terms of minimum RMSE where IWOA gets the least value. In addition, SDO beats both SATLBO and TLABC for the DDM, indicating SDO is more effective in solving this complex model. The test results show SDO is better than the nine algorithms except IJAYA. The convergence curves in Figure 7 show that IJAYA is the fastest while SDO maintains a relatively fast speed even at the later stage.

The extracted optimal parameters obtained by SDO are tabulated in Table 7, and the reconstructed I-V and P-V characteristic curves corresponding to these optimal parameters are presented in Figure 8. Figure 8 shows that the calculated data achieved by SDO with both the SDM and DDM are in good coincidence with the measured data. The IAE values in Table 8 are all smaller than 0.0004, which demonstrates the good accuracy of SDO again. Table 8 also reveals that the DDM provides a smaller value of the sum of IAE than the SDM, which results in an inference of good adaptability of the DDM for the PVM 752 GaAs thin film cell.

5.3. Results on the STM6-40/36 Monocrystalline Module. Table 9 presents the experimental results on the STM6-40/36 monocrystalline module. It clearly shows that SDO provides the least values in all terms of RMSE for both the SDM and DDM. In addition, the standard deviation values of SDO for both the SDM and DDM are at least one order of magnitude lower than those of the other compared algorithms, indicating its good robustness on this PV module. Wilcoxon's rank sum test results demonstrate that SDO is significantly better than ten and nine algorithms for the SDM and DDM, respectively. Both IJAYA and SDO get the similar result for the DDM statistically. The convergence curves in Figure 9 manifest that IJAYA still performs well but it is surpassed by 
TABLE 4: Extracted value for the parameters of the RTC France solar cell by SDO.

\begin{tabular}{lcccccccc}
\hline Model & $I_{\mathrm{ph}}(\mathrm{A})$ & $I_{\mathrm{sd} 1}(\mu \mathrm{A})$ & $R_{\mathrm{s}}(\Omega)$ & $R_{\mathrm{sh}}(\Omega)$ & $n_{1}$ & $I_{\mathrm{sd} 2}(\mu \mathrm{A})$ & $n_{2}$ & \multicolumn{2}{c}{ RMSE } \\
\hline SDM & 0.7608 & 0.3230 & 0.0364 & 53.7185 & 1.4812 & - & - & $9.8602 E-04$ \\
DDM & 0.7608 & 0.7879 & 0.0368 & 55.5705 & 2.0000 & 0.2214 & 1.4493 & $9.8250 E-04$ \\
\hline
\end{tabular}

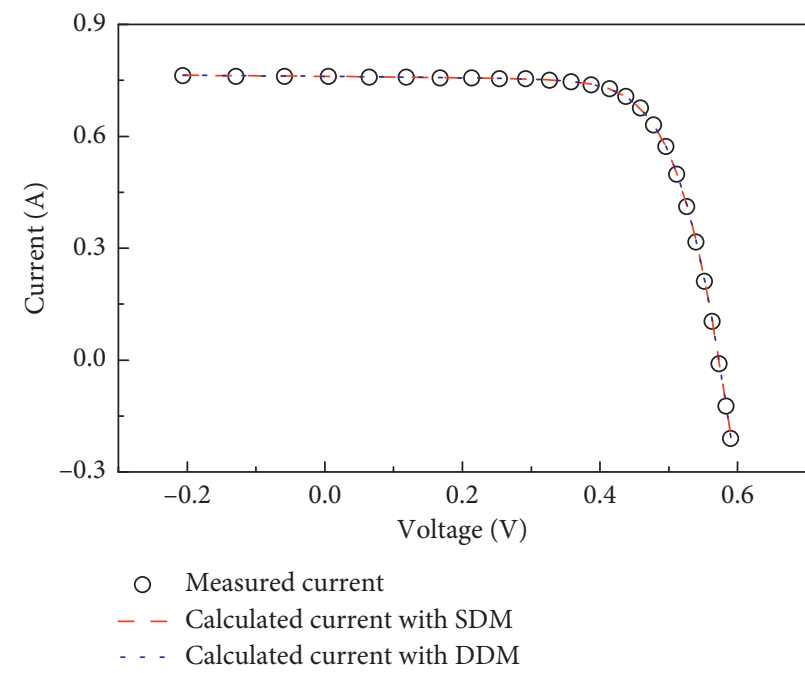

(a)

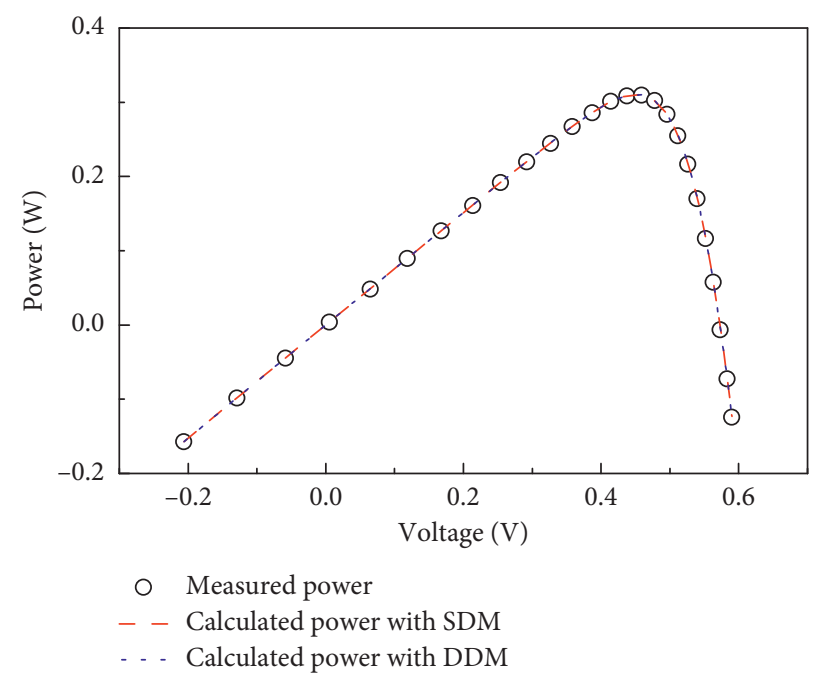

(b)

Figure 6: Comparison between the measured and calculated data achieved by SDO for the RTC France silicon solar cell. (a) I-V characteristic; (b) P-V characteristic.

TABLE 5: Calculated results for the RTC France solar cell by SDO.

\begin{tabular}{|c|c|c|c|c|c|c|}
\hline \multirow{2}{*}{ Item } & \multirow{2}{*}{$V_{\mathrm{L}}(\mathrm{V})$} & \multirow{2}{*}{$I_{\mathrm{L}}$ measured $(\mathrm{A})$} & \multicolumn{2}{|c|}{ SDM } & \multicolumn{2}{|c|}{ DDM } \\
\hline & & & $I_{\mathrm{L}}$ calculated $(\mathrm{A})$ & $\operatorname{IAE}(\mathrm{A})$ & $I_{\mathrm{L}}$ calculated $(\mathrm{A})$ & $\operatorname{IAE}(\mathrm{A})$ \\
\hline 1 & -0.2057 & 0.7640 & 0.76408765 & 0.00008765 & 0.76397865 & 0.00002135 \\
\hline 2 & -0.1291 & 0.7620 & 0.76266264 & 0.00066264 & 0.76260103 & 0.00060103 \\
\hline 3 & -0.0588 & 0.7605 & 0.76135473 & 0.00085473 & 0.76133641 & 0.00083641 \\
\hline 4 & 0.0057 & 0.7605 & 0.76015424 & 0.00034576 & 0.76017502 & 0.00032498 \\
\hline 5 & 0.0646 & 0.7600 & 0.75905593 & 0.00094407 & 0.75911090 & 0.00088910 \\
\hline 6 & 0.1185 & 0.7590 & 0.75804334 & 0.00095666 & 0.75812616 & 0.00087384 \\
\hline 7 & 0.1678 & 0.7570 & 0.75709159 & 0.00009159 & 0.75719293 & 0.00019293 \\
\hline 8 & 0.2132 & 0.7570 & 0.75614207 & 0.00085793 & 0.75624879 & 0.00075121 \\
\hline 9 & 0.2545 & 0.7555 & 0.75508732 & 0.00041268 & 0.75518142 & 0.00031858 \\
\hline 10 & 0.2924 & 0.7540 & 0.75366447 & 0.00033553 & 0.75372478 & 0.00027522 \\
\hline 11 & 0.3269 & 0.7505 & 0.75138806 & 0.00088806 & 0.75139526 & 0.00089526 \\
\hline 12 & 0.3585 & 0.7465 & 0.74734834 & 0.00084834 & 0.74729210 & 0.00079210 \\
\hline 13 & 0.3873 & 0.7385 & 0.74009688 & 0.00159688 & 0.73998463 & 0.00148463 \\
\hline 14 & 0.4137 & 0.7280 & 0.72739678 & 0.00060322 & 0.72725709 & 0.00074291 \\
\hline 15 & 0.4373 & 0.7065 & 0.70695328 & 0.00045328 & 0.70682936 & 0.00032936 \\
\hline 16 & 0.4590 & 0.6755 & 0.67529492 & 0.00020508 & 0.67522713 & 0.00027287 \\
\hline 17 & 0.4784 & 0.6320 & 0.63088433 & 0.00111567 & 0.63088881 & 0.00111119 \\
\hline 18 & 0.4960 & 0.5730 & 0.57208207 & 0.00091793 & 0.57214459 & 0.00085541 \\
\hline 19 & 0.5119 & 0.4990 & 0.49949167 & 0.00049167 & 0.49957588 & 0.00057588 \\
\hline 20 & 0.5265 & 0.4130 & 0.41349364 & 0.00049364 & 0.41356039 & 0.00056039 \\
\hline 21 & 0.5398 & 0.3165 & 0.31721950 & 0.00071950 & 0.31724334 & 0.00074334 \\
\hline 22 & 0.5521 & 0.2120 & 0.21210317 & 0.00010317 & 0.21207988 & 0.00007988 \\
\hline 23 & 0.5633 & 0.1035 & 0.10272136 & 0.00077864 & 0.10266820 & 0.00083180 \\
\hline 24 & 0.5736 & -0.0100 & -0.00924878 & 0.00075122 & -0.00930040 & 0.00069960 \\
\hline 25 & 0.5833 & -0.1230 & -0.12438136 & 0.00138136 & -0.12439113 & 0.00139113 \\
\hline 26 & 0.5900 & -0.2100 & -0.20919308 & 0.00080692 & -0.20914419 & 0.00085581 \\
\hline Sum & & & & 0.01770381 & & 0.01730620 \\
\hline
\end{tabular}


TABle 6: Experimental results on the PVM 752 GaAs thin film cell.

\begin{tabular}{|c|c|c|c|c|c|c|}
\hline Model & Algorithm & Min & Max & Mean & Std. dev. & Significance \\
\hline \multirow{11}{*}{ SDM } & CLPSO & $2.3769 E-04$ & $6.2527 E-04$ & $5.2031 E-04$ & $7.0536 E-05$ & $\dagger$ \\
\hline & $\mathrm{DE} / \mathrm{BBO}$ & $4.4257 E-04$ & $5.4430 E-04$ & $4.9571 E-04$ & $2.2319 E-05$ & $\dagger$ \\
\hline & GOTLBO & $2.9492 E-04$ & $4.9484 E-04$ & $4.0204 E-04$ & $4.7484 E-05$ & $\dagger$ \\
\hline & IJAYA & $2.2880 \mathrm{E}-04$ & $2.7167 E-04$ & $2.5378 \mathrm{E}-04$ & $1.1645 E-05$ & $¥$ \\
\hline & IWOA & $2.4740 E-04$ & $5.7399 E-04$ & $4.5156 E-04$ & $8.9898 E-05$ & $\dagger$ \\
\hline & LETLBO & $2.7261 E-04$ & $3.9623 E-04$ & $3.3354 E-04$ & $3.1904 E-05$ & $\dagger$ \\
\hline & MABC & $2.8780 E-04$ & $6.2992 E-04$ & $4.9864 E-04$ & $8.6429 E-05$ & $\dagger$ \\
\hline & ODE & $3.3079 E-04$ & $5.1531 E-04$ & $4.5800 E-04$ & $3.7762 E-05$ & $\dagger$ \\
\hline & SATLBO & $2.3507 E-04$ & $3.1341 E-04$ & $2.7396 E-04$ & $1.6165 E-05$ & $\ddagger$ \\
\hline & TLABC & $2.5814 E-04$ & $3.4267 E-04$ & $2.8923 E-04$ & $2.0936 E-05$ & $\ddagger$ \\
\hline & $\mathrm{SDO}$ & $2.3487 E-04$ & $3.7700 E-04$ & $3.1727 E-04$ & $2.7687 E-05$ & \\
\hline \multirow{11}{*}{ DDM } & CLPSO & $3.6535 E-04$ & $8.0492 E-04$ & $6.3929 E-04$ & $9.0095 E-05$ & $\dagger$ \\
\hline & $\mathrm{DE} / \mathrm{BBO}$ & $4.0709 E-04$ & $5.8587 E-04$ & $5.2992 E-04$ & $3.5679 E-05$ & $\dagger$ \\
\hline & GOTLBO & $3.0186 E-04$ & $5.5029 E-04$ & $4.1337 E-04$ & $6.0833 E-05$ & $\dagger$ \\
\hline & IJAYA & $2.1537 E-04$ & $3.5937 \mathrm{E}-04$ & $2.5929 E-04$ & $2.2873 E-05$ & $¥$ \\
\hline & IWOA & $2.0527 \mathrm{E}-04$ & $5.7609 E-04$ & $3.8642 E-04$ & $9.3900 E-05$ & $\dagger$ \\
\hline & LETLBO & $2.7139 E-04$ & $4.9192 E-04$ & $3.4188 E-04$ & $4.6623 E-05$ & $\dagger$ \\
\hline & MABC & $3.8852 E-04$ & $6.7013 E-04$ & $5.6206 E-04$ & $6.1736 E-05$ & $\dagger$ \\
\hline & ODE & $3.4568 E-04$ & $5.0415 E-04$ & $4.2829 E-04$ & $3.7022 E-05$ & $\dagger$ \\
\hline & SATLBO & $2.3785 E-04$ & $5.4593 E-04$ & $3.2119 E-04$ & $6.7473 E-05$ & $\dagger$ \\
\hline & TLABC & $2.3397 E-04$ & $5.8888 E-04$ & $3.4127 E-04$ & $5.9141 E-05$ & $\dagger$ \\
\hline & SDO & $2.1318 E-04$ & $4.7178 E-04$ & $2.8703 E-04$ & $5.1523 E-05$ & \\
\hline
\end{tabular}

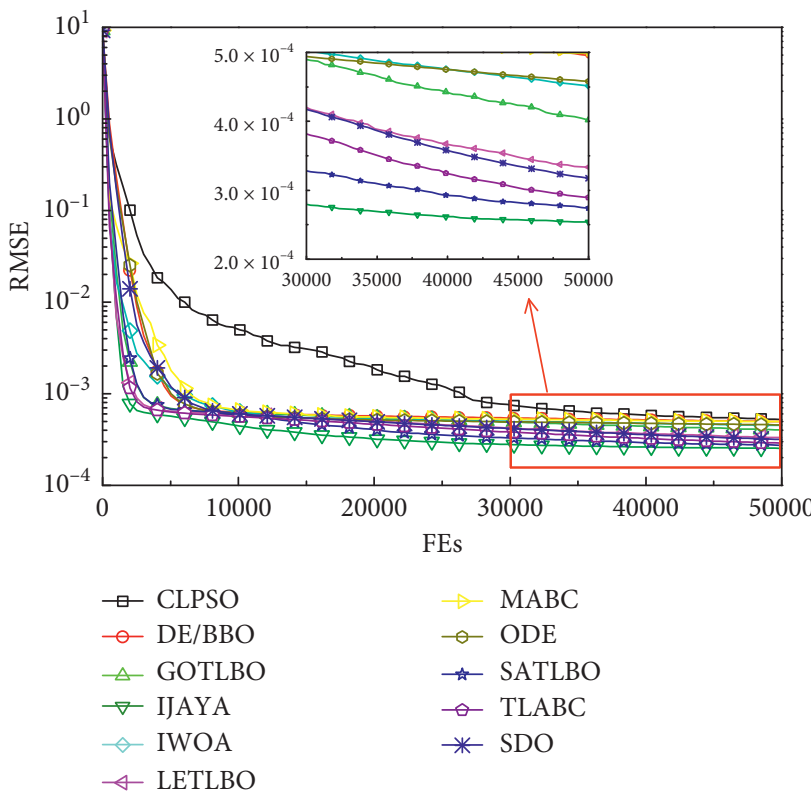

(a)

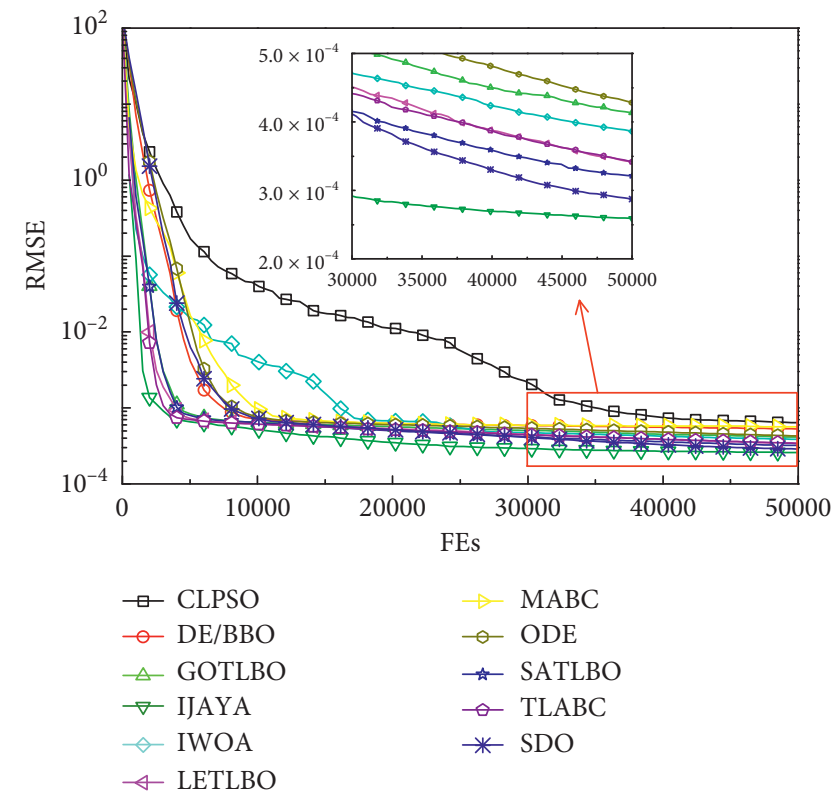

(b)

FIgURe 7: Convergence curves for the PVM 752 GaAs thin film cell. (a) SDM; (b) DDM.

TABLe 7: Extracted value for the parameters of PVM 752 GaAs thin film cell by SDO.

\begin{tabular}{lccccccrr}
\hline Model & $I_{\mathrm{ph}}(\mathrm{A})$ & $I_{\mathrm{sd} 1}(\mu \mathrm{A})$ & $R_{\mathrm{s}}(\Omega)$ & $R_{\mathrm{sh}}(\Omega)$ & $n_{1}$ & $I_{\mathrm{sd} 2}(\mu \mathrm{A})$ & $n_{2}$ & - \\
\hline SDM & 0.1000 & $5.9440 E-06$ & 0.6499 & 668.5946 & 1.6467 & - & $2.3487 E-04$ \\
DDM & 0.1001 & $7.2313 E-04$ & 0.6684 & 637.3026 & 2.0000 & $6.2352 E-05$ & 1.5152 & $2.1318 E-04$ \\
\hline
\end{tabular}

SDO after about 43000 and 31000 fitness evaluations for the SDM and DDM, respectively, indicating that SDO performs highly competitively at the later stage.
Table 10 reports the extracted optimal parameters yielded by SDO, and Figure 10 illustrates the reconstructed $\mathrm{I}-\mathrm{V}$ and $\mathrm{P}-\mathrm{V}$ characteristic curves. We can see that the 


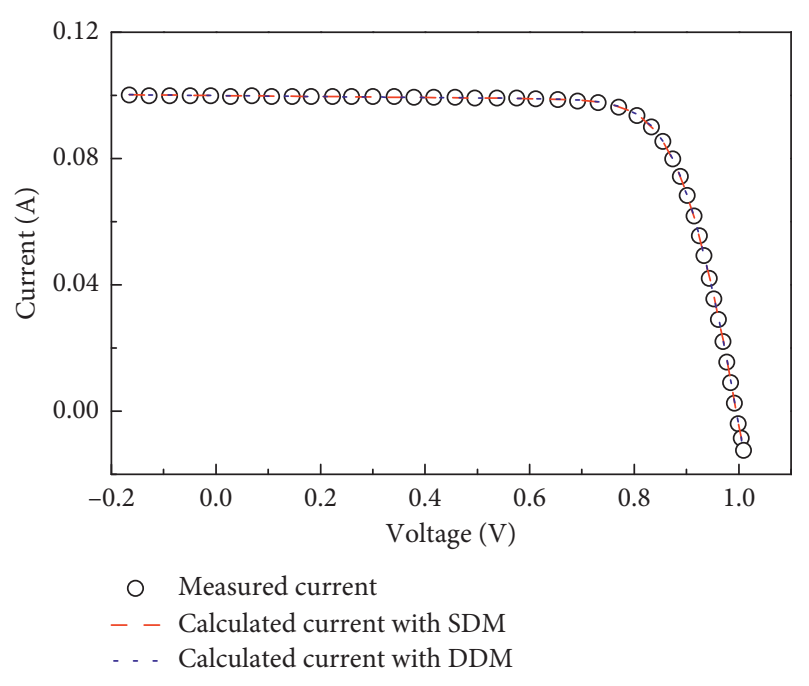

(a)

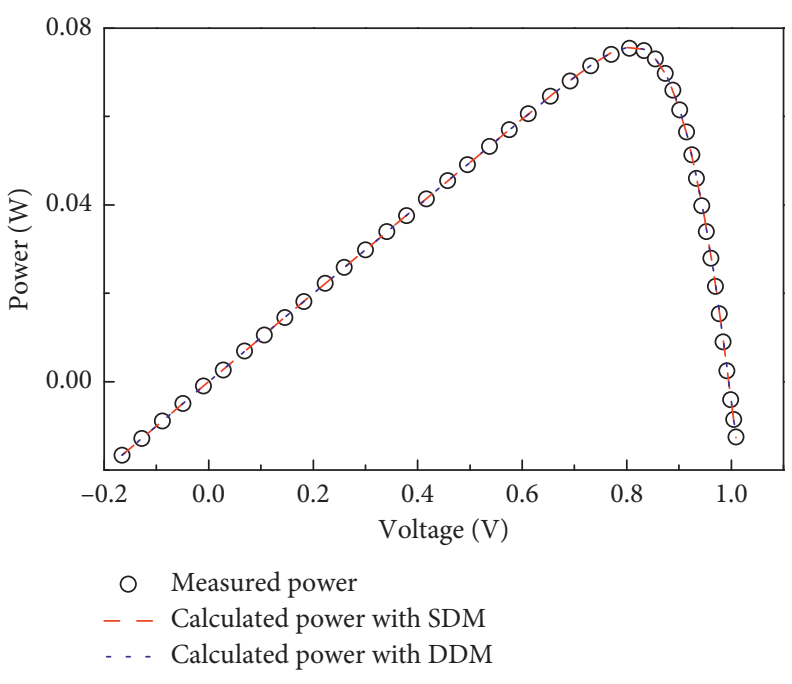

(b)

Figure 8: Comparison between the measured and calculated data achieved by SDO for the PVM 752 GaAs thin film cell. (a) I-V characteristic; (b) P-V characteristic.

calculated data achieved by SDO are in good agreement with the measured data over the entire voltage range. Besides, Table 11 shows that all of the IAE values are less than 0.00607 . Table 11 also testifies to that both the SDM and DDM obtain a comparable sum of IAE value, indicating that the DDM brings no benefit in terms of accuracy for the STM6-40/36 monocrystalline module. Moreover, Table 9 shows that the DDM gives larger values in all terms of RMSE except the minimum RMSE, meaning that the DDM is more complex and the solution algorithms are harder to get comparable results as those given by the SDM under the same considered condition (i.e., with the same Max_FEs).

5.4. Results on the STP6-120/36 Polycrystalline Module. With regards to the STP6-120/36 polycrystalline module, the experimental results tabulated in Table 12 show that ODE and SDO achieve the same least values $(1.6601 E-02)$ for both the SDM and DDM. However, SDO beats ODE in the rest terms of RMSE. Actually, Wilcoxon's rank sum test results also declare that SDO is significantly better than all of the other algorithms including ODE. The convergence curves in Figure 11 demonstrate that although SDO is relatively slow at the first stage, it has the ability of jumping out of local optima and keeping a relatively fast speed to search more promising areas at the later stage. Finally, it surpasses all compared algorithms after about 43000 and 46000 fitness evaluations for the SDM and DDM, respectively.

The extracted optimal parameters obtained by SDO are provided in Table 13. Using these parameters, the output currents and powers corresponding to the measured voltages can be calculated easily and they are summarized in Table 14 . It can be seen that all IAE values are less than 0.0375 . The reconstructed $\mathrm{I}-\mathrm{V}$ and $\mathrm{P}-\mathrm{V}$ characteristic curves presented in Figure 12 show again that the calculated data acquired by SDO with both the SDM and DDM all fit with the measured data well. Besides, although the value of sum of IAE given by the DDM in Table 14 is slightly smaller than that of the SDM, the difference $(0.00000089)$ is in practice very small, which concludes that both the SDM and DDM provide a similar accuracy for the STP6-120/36 polycrystalline module. Furthermore, Table 12 also proves that optimizing the DDM is more difficult than optimizing the SDM.

5.5. Overall Performance. In the above four sections, only the single-model statistical analysis by Wilcoxon's rank sum test is implemented to compare SDO with the other algorithms. As recommended in [57], the multiple-model statistical analysis that considers all the involved models simultaneously is also very momentous to verify the performance of SDO. In this section, the popular Friedman test at confidence level 0.05 is used to check the overall behavior of SDO in solving the problem concerned here. The test result is given in Figure 13. Clearly, SDO obtains the first overall best ranking, followed by IJAYA, TLABC, SATLBO, LETLBO, ODE, GOTLBO, DE/BBO, IWOA, CLPSO, and MABC. In conclusion, it can be confirmed by combining the single-model statistical analysis results in Tables 3, 6, 9, and 12 with the multiple-model statistical analysis result in Figure 13 that the overall performance of SDO is the best among all of involved algorithms in terms of the final solution quality, i.e., extraction accuracy.

5.6. Influence of Population Size on SDO. Population size is always a key parameter in metaheuristics and choosing an appropriate value is very important in solving different problems $[58,59]$. In this section, the influence of ps on SDO in solving the parameter extraction problem of PV models is investigated. Five values of ps from 10 to 50 with an interval of 10 are tested. The value of Max_FEs is kept the same as that in 
TABLe 8: Calculated results for the PVM 752 GaAs thin film cell by SDO.

\begin{tabular}{|c|c|c|c|c|c|c|}
\hline \multirow{2}{*}{ Item } & \multirow{2}{*}{$V_{\mathrm{L}}(\mathrm{V})$} & \multirow{2}{*}{$I_{\mathrm{L}}$ measured $(\mathrm{A})$} & \multicolumn{2}{|c|}{ SDM } & \multicolumn{2}{|c|}{$\mathrm{DDM}$} \\
\hline & & & $I_{\mathrm{L}}$ calculated $(\mathrm{A})$ & $\operatorname{IAE}(\mathrm{A})$ & $I_{\mathrm{L}}$ calculated $(\mathrm{A})$ & $\operatorname{IAE}(\mathrm{A})$ \\
\hline 1 & -0.1659 & 0.1001 & 0.10018154 & 0.00008154 & 0.10021151 & 0.00011151 \\
\hline 2 & -0.1281 & 0.1000 & 0.10012506 & 0.00012506 & 0.10015227 & 0.00015227 \\
\hline 3 & -0.0888 & 0.0999 & 0.10006634 & 0.00016634 & 0.10009069 & 0.00019069 \\
\hline 4 & -0.0490 & 0.0999 & 0.10000688 & 0.00010688 & 0.10002834 & 0.00012834 \\
\hline 5 & -0.0102 & 0.0999 & 0.09994894 & 0.00004894 & 0.09996763 & 0.00006763 \\
\hline 6 & 0.0275 & 0.0998 & 0.09989268 & 0.00009268 & 0.09990874 & 0.00010874 \\
\hline 7 & 0.0695 & 0.0999 & 0.09983014 & 0.00006986 & 0.09984342 & 0.00005658 \\
\hline 8 & 0.1061 & 0.0998 & 0.09977592 & 0.00002408 & 0.09978514 & 0.00001486 \\
\hline 9 & 0.1460 & 0.0998 & 0.09971549 & 0.00008451 & 0.09972260 & 0.00007740 \\
\hline 10 & 0.1828 & 0.0997 & 0.09966050 & 0.00003950 & 0.09966491 & 0.00003509 \\
\hline 11 & 0.2230 & 0.0997 & 0.09960043 & 0.00009957 & 0.09960189 & 0.00009811 \\
\hline 12 & 0.2600 & 0.0996 & 0.09954514 & 0.00005486 & 0.09954387 & 0.00005613 \\
\hline 13 & 0.3001 & 0.0997 & 0.09948520 & 0.00021480 & 0.09948096 & 0.00021904 \\
\hline 14 & 0.3406 & 0.0996 & 0.09942463 & 0.00017537 & 0.09941735 & 0.00018265 \\
\hline 15 & 0.3789 & 0.0995 & 0.09936727 & 0.00013273 & 0.09935706 & 0.00014294 \\
\hline 16 & 0.4168 & 0.0994 & 0.09931034 & 0.00008966 & 0.09929711 & 0.00010289 \\
\hline 17 & 0.4583 & 0.0994 & 0.09924747 & 0.00015253 & 0.09923068 & 0.00016932 \\
\hline 18 & 0.4949 & 0.0993 & 0.09919090 & 0.00010910 & 0.09917063 & 0.00012937 \\
\hline 19 & 0.5370 & 0.0993 & 0.09912292 & 0.00017708 & 0.09909827 & 0.00020173 \\
\hline 20 & 0.5753 & 0.0992 & 0.09905215 & 0.00014785 & 0.09902168 & 0.00017832 \\
\hline 21 & 0.6123 & 0.0990 & 0.09896636 & 0.00003364 & 0.09892948 & 0.00007052 \\
\hline 22 & 0.6546 & 0.0988 & 0.09881370 & 0.00001370 & 0.09876896 & 0.00003104 \\
\hline 23 & 0.6918 & 0.0983 & 0.09855916 & 0.00025916 & 0.09850763 & 0.00020763 \\
\hline 24 & 0.7318 & 0.0977 & 0.09797091 & 0.00027091 & 0.09792068 & 0.00022068 \\
\hline 25 & 0.7702 & 0.0963 & 0.09667172 & 0.00037172 & 0.09664210 & 0.00034210 \\
\hline 26 & 0.8053 & 0.0937 & 0.09407833 & 0.00037833 & 0.09409539 & 0.00039539 \\
\hline 27 & 0.8329 & 0.0900 & 0.09026480 & 0.00026480 & 0.09032920 & 0.00032920 \\
\hline 28 & 0.8550 & 0.0855 & 0.08546271 & 0.00003729 & 0.08555594 & 0.00005594 \\
\hline 29 & 0.8738 & 0.0799 & 0.07977453 & 0.00012547 & 0.07987373 & 0.00002627 \\
\hline 30 & 0.8887 & 0.0743 & 0.07405040 & 0.00024960 & 0.07413798 & 0.00016202 \\
\hline 31 & 0.9016 & 0.0683 & 0.06815879 & 0.00014121 & 0.06822618 & 0.00007382 \\
\hline 32 & 0.9141 & 0.0618 & 0.06159982 & 0.00020018 & 0.06164026 & 0.00015974 \\
\hline 33 & 0.9248 & 0.0555 & 0.05532216 & 0.00017784 & 0.05533722 & 0.00016278 \\
\hline 34 & 0.9344 & 0.0493 & 0.04918034 & 0.00011966 & 0.04917310 & 0.00012690 \\
\hline 35 & 0.9445 & 0.0422 & 0.04221514 & 0.00001514 & 0.04218800 & 0.00001200 \\
\hline 36 & 0.9533 & 0.0357 & 0.03574346 & 0.00004346 & 0.03570303 & 0.00000303 \\
\hline 37 & 0.9618 & 0.0291 & 0.02915271 & 0.00005271 & 0.02910474 & 0.00000474 \\
\hline 38 & 0.9702 & 0.0222 & 0.02232790 & 0.00012790 & 0.02227858 & 0.00007858 \\
\hline 39 & 0.9778 & 0.0157 & 0.01589993 & 0.00019993 & 0.01585531 & 0.00015531 \\
\hline 40 & 0.9852 & 0.0092 & 0.00942200 & 0.00022200 & 0.00938796 & 0.00018796 \\
\hline 41 & 0.9926 & 0.0026 & 0.00273929 & 0.00013929 & 0.00272204 & 0.00012204 \\
\hline 42 & 0.9999 & -0.0040 & -0.00404317 & 0.00004317 & -0.00403767 & 0.00003767 \\
\hline 43 & 1.0046 & -0.0085 & -0.00850506 & 0.00000506 & -0.00848146 & 0.00001854 \\
\hline 44 & 1.0089 & -0.0124 & -0.01264980 & 0.00024980 & -0.01260726 & 0.00020726 \\
\hline Sum & & & & 0.00593491 & & 0.00561477 \\
\hline
\end{tabular}

Section 5.1. The experimental results over 50 independent runs are illustrated in Figure 14. It is obvious that ps does affect the performance of SDO. Specifically, a smaller value (e.g. $\leq 20)$ is beneficial to SDO. When the value of ps exceeds 20, the larger the value of ps, the worser the performance of SDO. In addition, SDO obtains the best mean RMSE values with $\mathrm{ps}=20$ on three PV models including the RTC France silicon solar cell, STM6-40/36 monocrystalline module, and STP6-120/36 polycrystalline module. While on the PVM $752 \mathrm{GaAs}$ thin film cell, SDO with ps $=10$ is slightly better than that with $\mathrm{ps}=20$. The main reasons are as follows: (i) The parameter extraction problem of PV models belongs to a low-dimensional optimization problem. There is no need to set a relatively large population. Notwithstanding enriching the population diversity with a large population, all markets (i.e., individuals) scatter in the whole search domain, which is not good for the convergence. Additionally, a large population means that a considerable number of fitness evaluations will be expended, especially that SDO expends $2 \times$ ps fitness evaluations at each iteration. In this context, the number of iterations will 
TABLE 9: Experimental results on the STM6-40/36 module.

\begin{tabular}{|c|c|c|c|c|c|c|}
\hline Model & Algorithm & Min & Max & Mean & Std. dev. & Significance \\
\hline \multirow{11}{*}{ SDM } & CLPSO & $2.3723 E-03$ & $1.1682 E-02$ & $4.4191 E-03$ & $1.5097 E-03$ & + \\
\hline & $\mathrm{DE} / \mathrm{BBO}$ & $2.3456 E-03$ & $3.0233 E-03$ & $2.6869 E-03$ & $1.6177 E-04$ & $\dagger$ \\
\hline & GOTLBO & $1.9424 E-03$ & $3.3244 E-03$ & $2.7496 E-03$ & $2.9176 E-04$ & $\dagger$ \\
\hline & IJAYA & $1.7344 E-03$ & $2.4448 E-03$ & $1.8070 E-03$ & $1.1705 E-04$ & $\dagger$ \\
\hline & IWOA & $1.7326 E-03$ & $3.9651 E-03$ & $2.7463 E-03$ & $5.1334 E-04$ & $\dagger$ \\
\hline & LETLBO & $1.7385 E-03$ & $3.3171 E-03$ & $2.4289 E-03$ & $4.2059 E-04$ & $\dagger$ \\
\hline & MABC & $3.0221 E-03$ & $3.0890 E-02$ & $1.0045 E-02$ & $6.7529 E-03$ & $\dagger$ \\
\hline & ODE & $2.1744 E-03$ & $3.2718 E-03$ & $2.7751 E-03$ & $2.4512 E-04$ & $\dagger$ \\
\hline & SATLBO & $1.7469 E-03$ & $2.4915 E-03$ & $1.9018 E-03$ & $1.2036 E-04$ & $\dagger$ \\
\hline & TLABC & $1.7338 E-03$ & $2.1368 E-03$ & $1.8602 E-03$ & $1.0641 E-04$ & $\dagger$ \\
\hline & SDO & $1.7298 \mathrm{E}-03$ & $1.9500 \mathrm{E}-03$ & $1.7703 \mathrm{E}-03$ & $4.5108 \mathrm{E}-05$ & \\
\hline \multirow{11}{*}{ DDM } & CLPSO & $2.7951 E-03$ & $1.0415 E-02$ & $4.3612 E-03$ & $1.2092 E-03$ & + \\
\hline & $\mathrm{DE} / \mathrm{BBO}$ & $2.3524 E-03$ & $3.0713 E-03$ & $2.7546 E-03$ & $1.7561 E-04$ & $\dagger$ \\
\hline & GOTLBO & $2.3605 E-03$ & $4.7391 E-03$ & $3.4289 E-03$ & $6.0545 E-04$ & $\dagger$ \\
\hline & IJAYA & $1.7310 E-03$ & $2.7828 E-03$ & $1.8875 E-03$ & $2.2946 E-04$ & $\approx$ \\
\hline & IWOA & $1.7305 E-03$ & $3.7688 E-03$ & $2.8740 E-03$ & $5.2943 E-04$ & $\dagger$ \\
\hline & LETLBO & $1.7646 E-03$ & $3.6799 E-03$ & $2.7820 E-03$ & $4.4982 E-04$ & $\dagger$ \\
\hline & MABC & $3.1313 E-03$ & $2.5346 E-02$ & $1.0901 E-02$ & $6.7349 E-03$ & $\dagger$ \\
\hline & ODE & $2.4339 E-03$ & $3.2422 E-03$ & $2.8297 E-03$ & $2.0219 E-04$ & + \\
\hline & SATLBO & $1.7556 E-03$ & $4.2588 E-03$ & $1.9882 E-03$ & $3.4909 E-04$ & + \\
\hline & TLABC & $1.7348 E-03$ & $2.1727 E-03$ & $1.8917 E-03$ & $1.0598 E-04$ & $\dagger$ \\
\hline & SDO & $1.7298 \mathrm{E}-03$ & $2.0288 E-03$ & $1.8118 \mathrm{E}-03$ & $7.2421 \mathrm{E}-05$ & \\
\hline
\end{tabular}

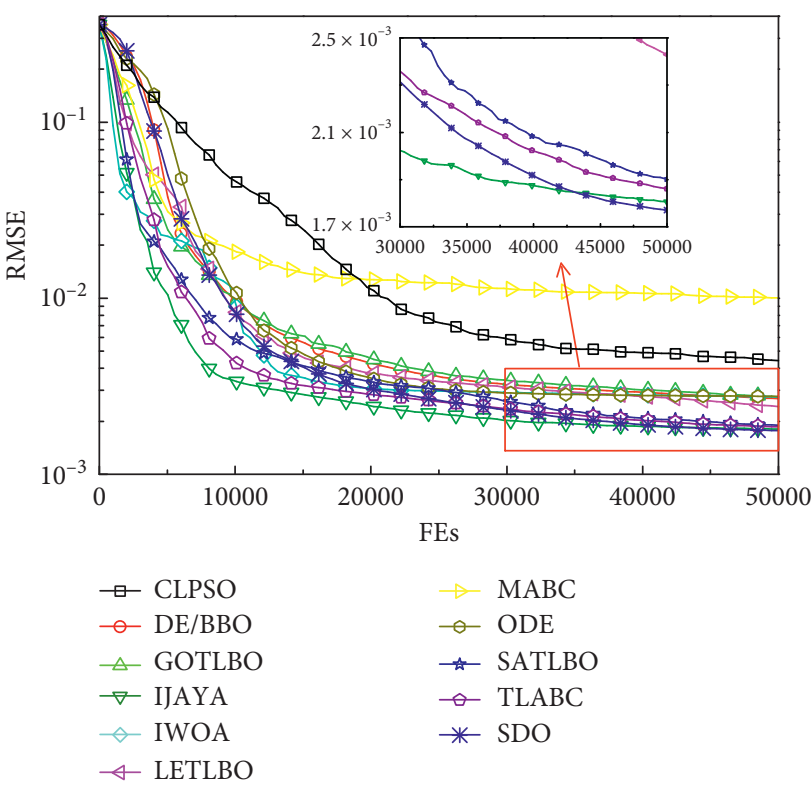

(a)

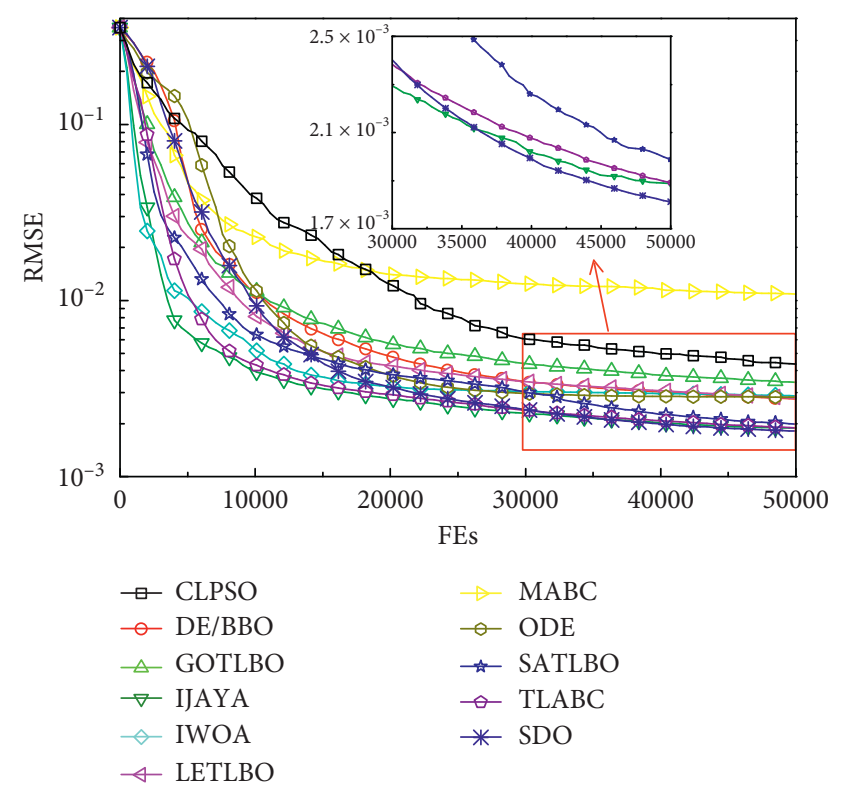

(b)

FIgURE 9: Convergence curves for the STM6-40/36 monocrystalline module. (a) SDM; (b) DDM.

be decreased significantly under a given Max_FEs, which is not conducive to low-dimensional optimization problems.

(ii) The problem considered here is a typical multimodal optimization problem with many local minima. Although a very small population size can increase the number of iterations, the population diversity is low, resulting in poor possible movements of individuals. All individuals are easy to swarm towards a certain local optima and thereby suffer from premature convergence. For example, we can see from Figure 14 that SDO with ps $=10$ suffers from premature convergence frequently leading to relatively large values of RMSE over 50 runs on many cases such as Figures 14(a), 14(b), 14(f), and 14(g).

In fact, there is no axiom or rule that can be used to determine a proper population size for different optimization problems so far. With regards to the problem 
TABLE 10: Extracted value for the parameters of the STM6-40/36 module by SDO.

\begin{tabular}{lccccccrr}
\hline Model & $I_{\mathrm{ph}}(\mathrm{A})$ & $I_{\mathrm{sd} 1}(\mu \mathrm{A})$ & $R_{\mathrm{s}}(\Omega)$ & $R_{\mathrm{sh}}(\Omega)$ & $n_{1}$ & $I_{\mathrm{sd} 2}(\mu \mathrm{A})$ & $n_{2}$ & \multicolumn{1}{c}{ RMSE } \\
\hline SDM & 1.6639 & 1.7387 & 0.0043 & 15.9283 & 1.5203 & - & - & $1.7298 E-03$ \\
DDM & 1.6639 & 1.7385 & 0.0043 & 15.9372 & 1.5203 & 49.9985 & 54.5816 & $1.7298 E-03$ \\
\hline
\end{tabular}

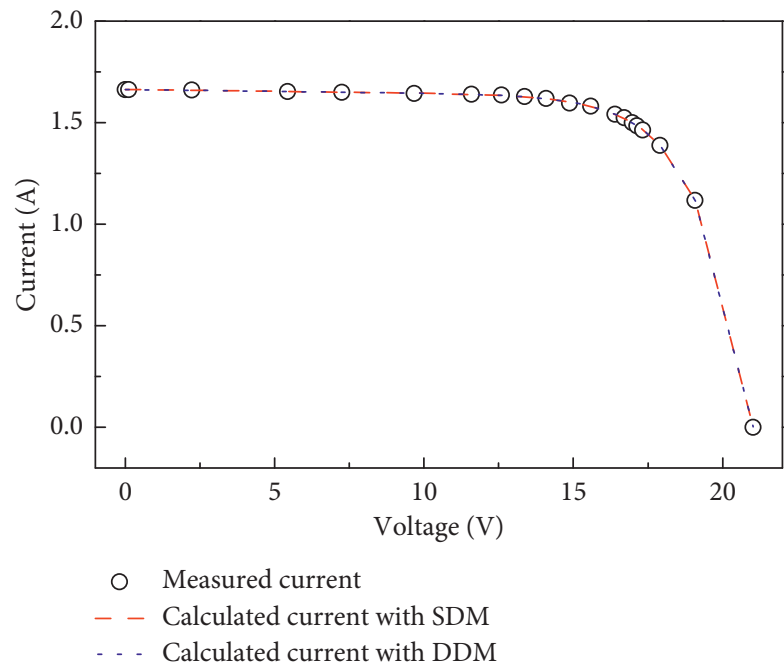

(a)

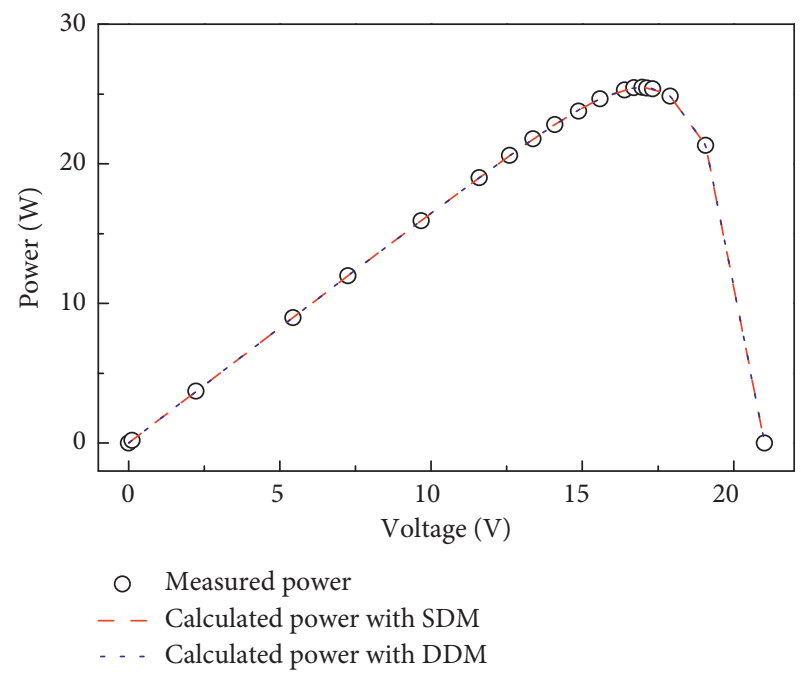

(b)

FIgURE 10: Comparison between the measured and calculated data achieved by SDO for the STM6-40/36 monocrystalline module. (a) I-V characteristic; (b) P-V characteristic.

TABLE 11: Calculated results for the STM6-40/36 module by SDO.

\begin{tabular}{|c|c|c|c|c|c|c|}
\hline \multirow{2}{*}{ Item } & \multirow{2}{*}{$V_{\mathrm{L}}(\mathrm{V})$} & \multirow{2}{*}{$I_{\mathrm{L}}$ measured $(\mathrm{A})$} & \multicolumn{2}{|c|}{ SDM } & \multicolumn{2}{|c|}{ DDM } \\
\hline & & & $I_{\mathrm{L}}$ calculated $(\mathrm{A})$ & IAE (A) & $I_{\mathrm{L}}$ calculated $(\mathrm{A})$ & $\operatorname{IAE}(\mathrm{A})$ \\
\hline 1 & 0.0000 & 1.6630 & 1.66345813 & 0.00045813 & 1.66345837 & 0.00045837 \\
\hline 2 & 0.1180 & 1.6630 & 1.66325224 & 0.00025224 & 1.66325248 & 0.00025248 \\
\hline 3 & 2.2370 & 1.6610 & 1.65955120 & 0.00144880 & 1.65955152 & 0.00144848 \\
\hline 4 & 5.4340 & 1.6530 & 1.65391445 & 0.00091445 & 1.65391477 & 0.00091477 \\
\hline 5 & 7.2600 & 1.6500 & 1.65056577 & 0.00056577 & 1.65056600 & 0.00056600 \\
\hline 6 & 9.6800 & 1.6450 & 1.64543056 & 0.00043056 & 1.64543061 & 0.00043061 \\
\hline 7 & 11.5900 & 1.6400 & 1.63923444 & 0.00076556 & 1.63923432 & 0.00076568 \\
\hline 8 & 12.6000 & 1.6360 & 1.63371579 & 0.00228421 & 1.63371559 & 0.00228441 \\
\hline 9 & 13.3700 & 1.6290 & 1.62728848 & 0.00171152 & 1.62728824 & 0.00171176 \\
\hline 10 & 14.0900 & 1.6190 & 1.61831518 & 0.00068482 & 1.61831493 & 0.00068507 \\
\hline 11 & 14.8800 & 1.5970 & 1.60306738 & 0.00606738 & 1.60306715 & 0.00606715 \\
\hline 12 & 15.5900 & 1.5810 & 1.58158500 & 0.00058500 & 1.58158482 & 0.00058482 \\
\hline 13 & 16.4000 & 1.5420 & 1.54232828 & 0.00032828 & 1.54232820 & 0.00032820 \\
\hline 14 & 16.7100 & 1.5240 & 1.52122523 & 0.00277477 & 1.52122518 & 0.00277482 \\
\hline 15 & 16.9800 & 1.5000 & 1.49920572 & 0.00079428 & 1.49920570 & 0.00079430 \\
\hline 16 & 17.1300 & 1.4850 & 1.48527115 & 0.00027115 & 1.48527114 & 0.00027114 \\
\hline 17 & 17.3200 & 1.4650 & 1.46564321 & 0.00064321 & 1.46564322 & 0.00064322 \\
\hline 18 & 17.9100 & 1.3880 & 1.38759934 & 0.00040066 & 1.38759934 & 0.00040066 \\
\hline 19 & 19.0800 & 1.1180 & 1.11837210 & 0.00037210 & 1.11837178 & 0.00037178 \\
\hline 20 & 21.0200 & 0.0000 & -0.00002129 & 0.00002129 & -0.00002130 & 0.00002130 \\
\hline \multicolumn{2}{|c|}{ Sum of IAE } & & & 0.02177419 & & 0.02177500 \\
\hline
\end{tabular}

considered in this work, it is recommended to set a moderate value with $\mathrm{ps}=20$ for SDO.

5.7. Comparison with Reported Results. In order to further verify the performance of SDO in solving the parameter extraction problem of PV models, its results are compared with the reported results of some well-designed parameter extraction algorithms on the RTC France silicon solar cell. The comparison results are presented in Table 15. It shows that SDO is highly competitive. For the SDM, although it is worse than RF, RSS, and TSLLS, it is better than or similar 
TABLE 12: Experimental results on the STP6-120/36 module.

\begin{tabular}{|c|c|c|c|c|c|c|}
\hline Model & Algorithm & Min & Max & Mean & Std. dev. & Significance \\
\hline \multirow{11}{*}{ SDM } & CLPSO & $1.6963 E-02$ & $4.1099 E-02$ & $2.3735 E-02$ & $5.8696 E-03$ & + \\
\hline & $\mathrm{DE} / \mathrm{BBO}$ & $2.4232 E-02$ & $3.5363 E-02$ & $2.8826 E-02$ & $2.6045 E-03$ & $\dagger$ \\
\hline & GOTLBO & $1.7125 E-02$ & $3.4055 E-02$ & $2.1265 E-02$ & $3.3083 E-03$ & $\dagger$ \\
\hline & IJAYA & $1.6622 E-02$ & $1.6953 E-02$ & $1.6799 E-02$ & $7.3789 E-05$ & $\dagger$ \\
\hline & IWOA & $1.6607 E-02$ & $1.2215 E-01$ & $2.7637 E-02$ & $1.4981 E-02$ & $\dagger$ \\
\hline & LETLBO & $1.6780 E-02$ & $4.6301 E-02$ & $1.9915 E-02$ & $4.9607 E-03$ & $\dagger$ \\
\hline & MABC & $1.7238 E-02$ & $5.4369 E-02$ & $4.0777 E-02$ & $8.9788 E-03$ & $\dagger$ \\
\hline & ODE & $1.6601 \mathrm{E}-02$ & $3.9657 E-02$ & $2.5704 E-02$ & $6.4560 E-03$ & $\dagger$ \\
\hline & SATLBO & $1.6652 E-02$ & $1.8713 E-02$ & $1.7042 E-02$ & $3.9219 E-04$ & $\dagger$ \\
\hline & TLABC & $1.6605 E-02$ & $1.7300 E-02$ & $1.6784 E-02$ & $1.6458 E-04$ & $\dagger$ \\
\hline & $\mathrm{SDO}$ & $1.6601 \mathrm{E}-02$ & $1.6866 \mathrm{E}-02$ & $1.6683 E-02$ & $7.1751 \mathrm{E}-05$ & \\
\hline \multirow{11}{*}{ DDM } & CLPSO & $1.6879 E-02$ & $4.7602 E-02$ & $2.5034 E-02$ & $6.7086 E-03$ & + \\
\hline & $\mathrm{DE} / \mathrm{BBO}$ & $2.1421 E-02$ & $3.6806 E-02$ & $2.9386 E-02$ & $2.9562 E-03$ & $\dagger$ \\
\hline & GOTLBO & $1.7208 E-02$ & $4.3479 E-02$ & $2.6040 E-02$ & $7.2481 E-03$ & $\dagger$ \\
\hline & IJAYA & $1.6632 E-02$ & $1.7935 E-02$ & $1.6823 E-02$ & $1.7512 E-04$ & $\dagger$ \\
\hline & IWOA & $1.6629 E-02$ & $4.0750 E-02$ & $2.2580 E-02$ & $5.2119 E-03$ & + \\
\hline & LETLBO & $1.6828 E-02$ & $3.1588 E-02$ & $1.9795 E-02$ & $3.0745 E-03$ & $\dagger$ \\
\hline & MABC & $1.8634 E-02$ & $5.5329 E-02$ & $4.2947 E-02$ & $9.3427 E-03$ & $\dagger$ \\
\hline & ODE & $1.6601 \mathrm{E}-02$ & $3.8352 E-02$ & $2.5832 E-02$ & $6.3294 E-03$ & + \\
\hline & SATLBO & $1.6678 E-02$ & $1.9395 E-02$ & $1.7107 E-02$ & $4.8711 E-04$ & $\dagger$ \\
\hline & TLABC & $1.6633 E-02$ & $1.8324 E-02$ & $1.6836 E-02$ & $2.5365 E-04$ & + \\
\hline & SDO & $1.6601 \mathrm{E}-02$ & $1.7268 \mathrm{E}-02$ & $1.6741 \mathrm{E}-02$ & $1.2362 \mathrm{E}-04$ & \\
\hline
\end{tabular}

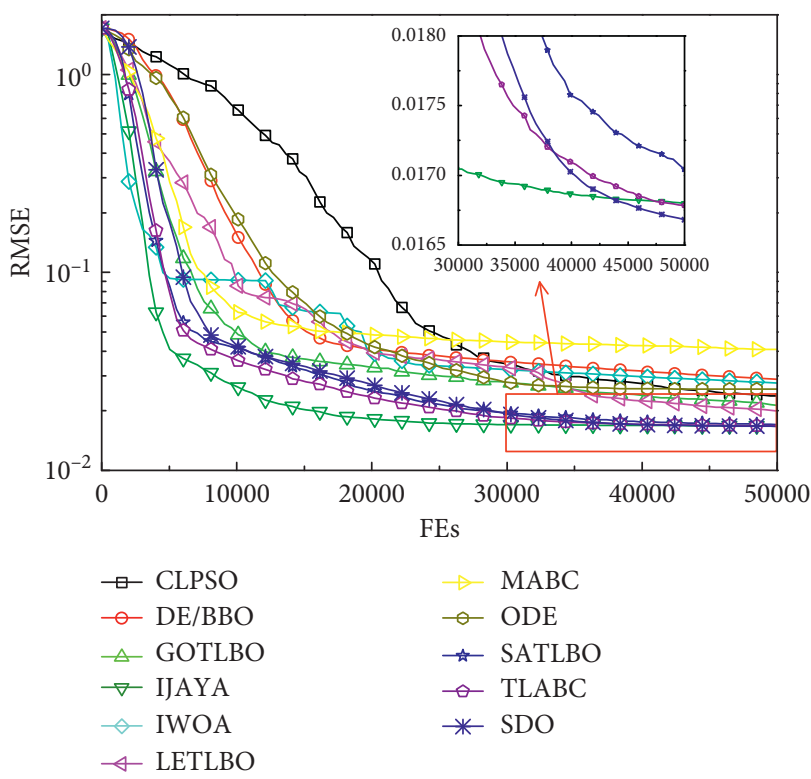

(a)

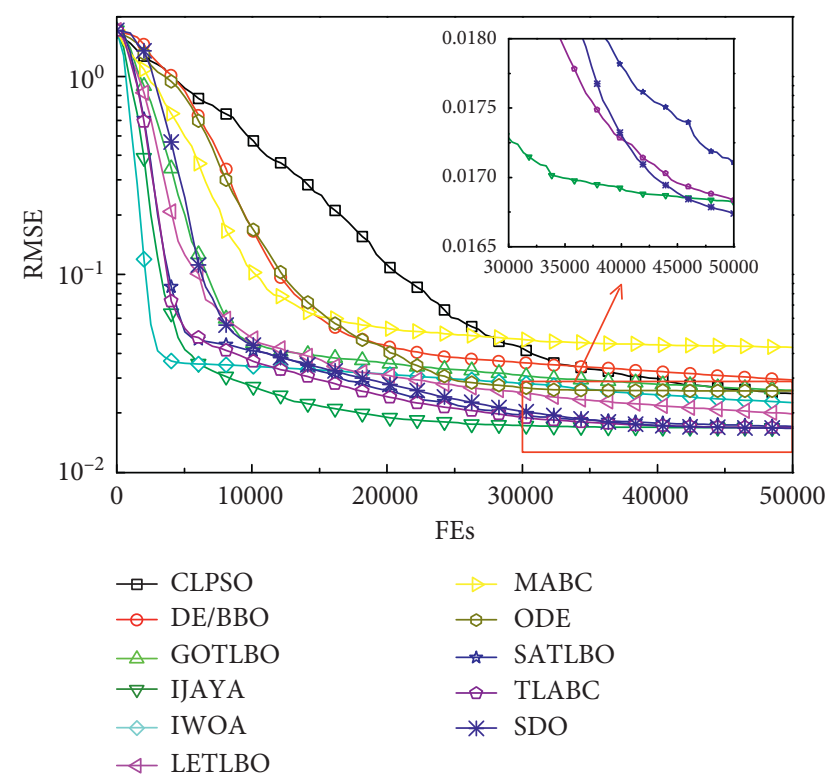

(b)

FIgURE 11: Convergence curves for the STP6-120/36 polycrystalline module. (a) SDM; (b) DDM.

TABLE 13: Extracted value for the parameters of STP6-120/36 module by SDO.

\begin{tabular}{lccccccrr}
\hline Model & $I_{\mathrm{ph}}(\mathrm{A})$ & $I_{\mathrm{sd} 1}(\mu \mathrm{A})$ & $R_{\mathrm{s}}(\Omega)$ & $R_{\mathrm{sh}}(\Omega)$ & $n_{1}$ & $I_{\mathrm{sd} 2}(\mu \mathrm{A})$ & $n_{2}$ & \multicolumn{1}{c}{ RMSE } \\
\hline SDM & 7.4725 & 2.3350 & 0.0046 & 22.2199 & 1.2601 & - & - & $1.6601 E-02$ \\
DDM & 7.4725 & $6.1168 E-02$ & 0.0046 & 22.2350 & 48.2465 & 2.3354 & 1.2601 & $1.6601 E-02$ \\
\hline
\end{tabular}

to other algorithms in terms of the minimum RMSE value. For the DDM, SDO achieves a very competitive minimum RMSE value that is only slightly larger than that of ABC-TRR.
Additionally, in terms of other RMSE values, SDO also yields comparable performance. In summary, the comparison demonstrates the good performance of SDO once again. 
TABLE 14: Calculated results for the STP6-120/36 module by SDO.

\begin{tabular}{|c|c|c|c|c|c|c|}
\hline \multirow{2}{*}{ Item } & \multirow{2}{*}{$V_{\mathrm{L}}(\mathrm{V})$} & \multirow{2}{*}{$I_{\mathrm{L}}$ measured $(\mathrm{A})$} & \multicolumn{2}{|c|}{ SDM } & \multicolumn{2}{|c|}{ DDM } \\
\hline & & & $I_{\mathrm{L}}$ calculated $(\mathrm{A})$ & $\operatorname{IAE}(\mathrm{A})$ & $I_{\mathrm{L}}$ calculated $(\mathrm{A})$ & $\operatorname{IAE}(\mathrm{A})$ \\
\hline 1 & 19.2100 & 0.0000 & 0.00116434 & 0.00116434 & 0.00115600 & 0.00115600 \\
\hline 2 & 17.6500 & 3.8300 & 3.83228233 & 0.00228233 & 3.83228460 & 0.00228460 \\
\hline 3 & 17.4100 & 4.2900 & 4.27392911 & 0.01607089 & 4.27393114 & 0.01606886 \\
\hline 4 & 17.2500 & 4.5600 & 4.54628987 & 0.01371013 & 4.54629162 & 0.01370838 \\
\hline 5 & 17.1000 & 4.7900 & 4.78583302 & 0.00416698 & 4.78583443 & 0.00416557 \\
\hline 6 & 16.9000 & 5.0700 & 5.08193389 & 0.01193389 & 5.08193481 & 0.01193481 \\
\hline 7 & 16.7600 & 5.2700 & 5.27376516 & 0.00376516 & 5.27376571 & 0.00376571 \\
\hline 8 & 16.3400 & 5.7500 & 5.77681381 & 0.02681381 & 5.77681335 & 0.02681335 \\
\hline 9 & 16.0800 & 6.0000 & 6.03749239 & 0.03749239 & 6.03749146 & 0.03749146 \\
\hline 10 & 15.7100 & 6.3600 & 6.34872743 & 0.01127257 & 6.34872610 & 0.01127390 \\
\hline 11 & 15.3900 & 6.5800 & 6.56792937 & 0.01207063 & 6.56792798 & 0.01207202 \\
\hline 12 & 14.9300 & 6.8300 & 6.81486011 & 0.01513989 & 6.81485901 & 0.01514099 \\
\hline 13 & 14.5800 & 6.9700 & 6.95844905 & 0.01155095 & 6.95844839 & 0.01155161 \\
\hline 14 & 14.1700 & 7.1000 & 7.08813731 & 0.01186269 & 7.08813732 & 0.01186268 \\
\hline 15 & 13.5900 & 7.2300 & 7.21776104 & 0.01223896 & 7.21776204 & 0.01223796 \\
\hline 16 & 13.1600 & 7.2900 & 7.28413003 & 0.00586997 & 7.28413171 & 0.00586829 \\
\hline 17 & 12.7400 & 7.3400 & 7.33148314 & 0.00851686 & 7.33148538 & 0.00851462 \\
\hline 18 & 12.3600 & 7.3700 & 7.36326482 & 0.00673518 & 7.36326746 & 0.00673254 \\
\hline 19 & 11.8100 & 7.3800 & 7.39587315 & 0.01587315 & 7.39587620 & 0.01587620 \\
\hline 20 & 11.1700 & 7.4100 & 7.42026500 & 0.01026500 & 7.42026828 & 0.01026828 \\
\hline 21 & 10.3200 & 7.4400 & 7.43909223 & 0.00090777 & 7.43909549 & 0.00090451 \\
\hline 22 & 9.7400 & 7.4200 & 7.44671497 & 0.02671497 & 7.44671805 & 0.02671805 \\
\hline 23 & 9.0600 & 7.4500 & 7.45253755 & 0.00253755 & 7.45254032 & 0.00254032 \\
\hline 24 & 0.0000 & 7.4800 & 7.47098178 & 0.00901822 & 7.47097731 & 0.00902269 \\
\hline \multicolumn{2}{|c|}{ Sum of IAE } & & & 0.27797428 & & 0.27797339 \\
\hline
\end{tabular}

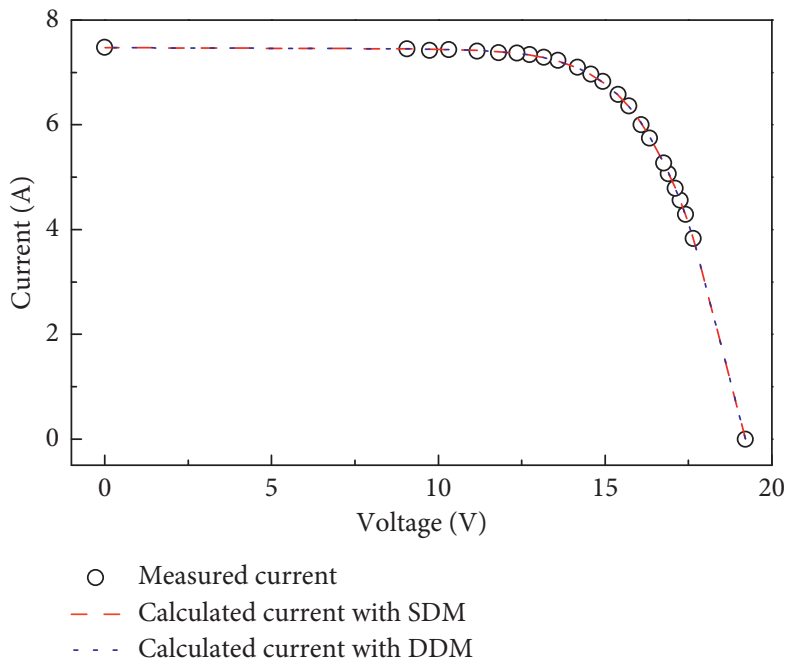

(a)

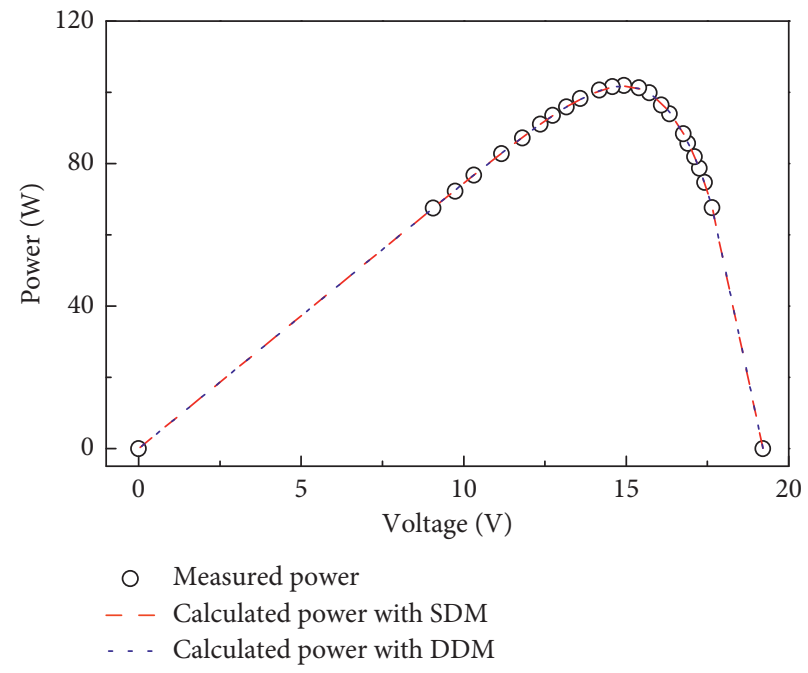

(b)

FIgURE 12: Comparison between the measured and calculated data achieved by SDO for the STP6-120/36 polycrystalline module. (a) I-V characteristic; (b) P-V characteristic.

\section{Conclusions and Future Work}

SDO is a very new and effective metaheuristic. In this paper, SDO is first applied to the parameter extraction problem of PV models. Its feasibility and effectiveness are experimentally verified via four PV models including cells and modules with different characteristics. The experimental results summarize that (i) SDO performs better or competitively compared with other well-designed algorithms according to both simulation results and Wilcoxon's rank sum test results. It, overall, obtains the first ranking according to the Friedman test.

(ii) SDO exhibits good convergence property especially at the later stage of evolutionary process, indicating 


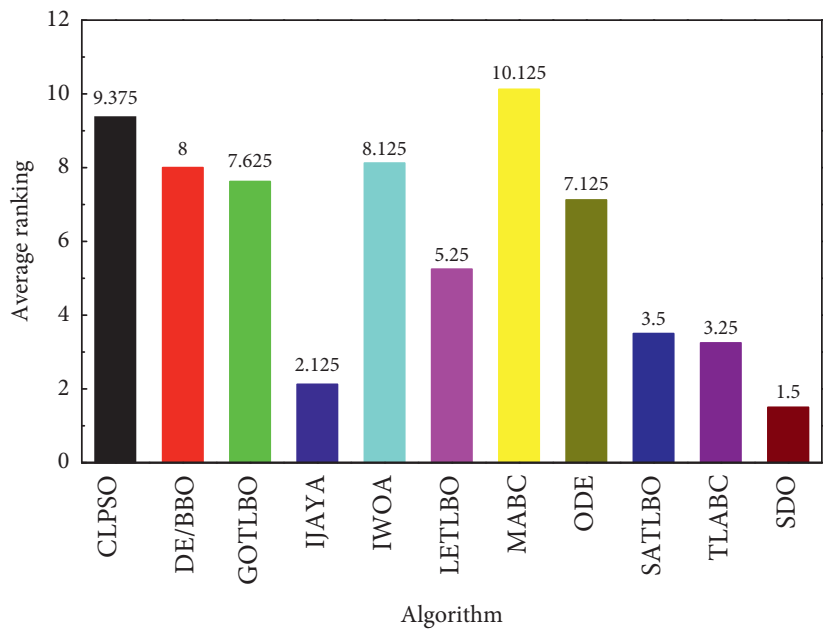

Figure 13: Friedman test result.

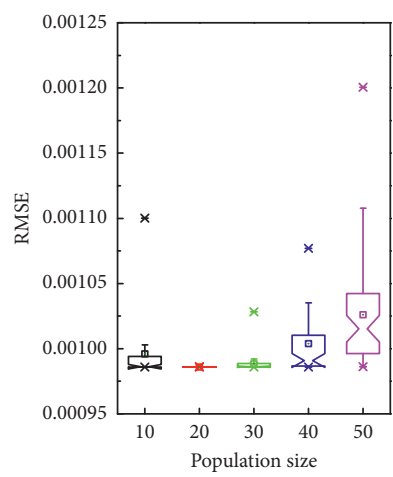

(a)

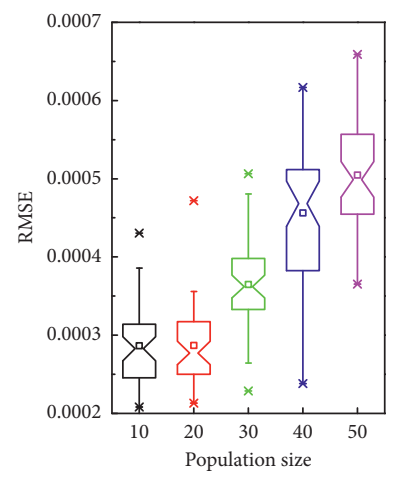

(d)

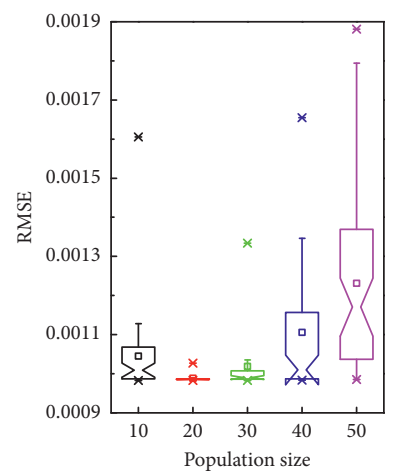

(b)

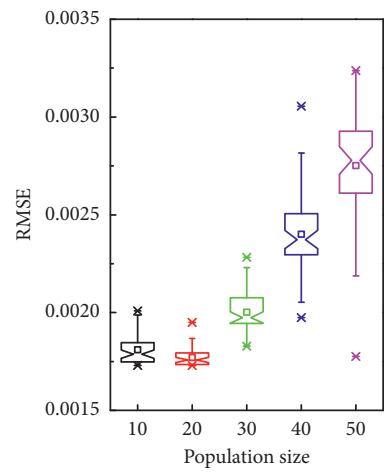

(e)

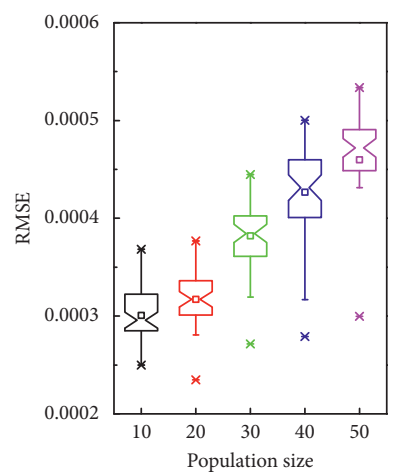

(c)

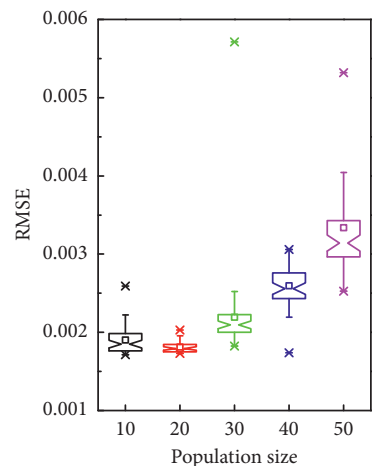

(f)

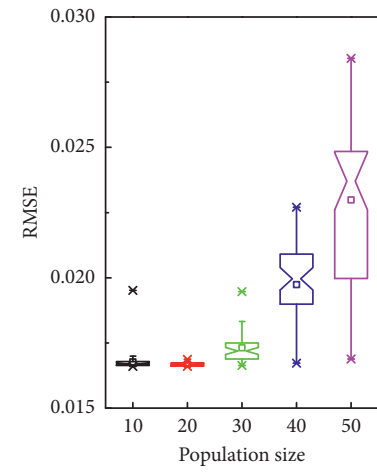

(g)

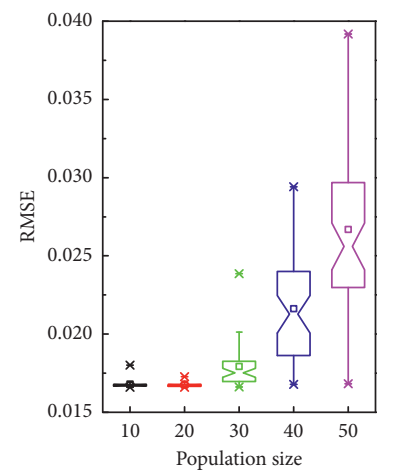

(h)

FIGURE 14: Influence of population size on SDO. (a) RTC France silicon solar cell with the SDM; (b) RTC France silicon solar cell with DDM; (c) PVM 752 GaAs thin film cell with the SDM; (d) PVM 752 GaAs thin film cell with the DDM; (e) STM6-40/36 monocrystalline module with the SDM; (f) STM6-40/36 monocrystalline module with the DDM; (g) STP6-120/36 polycrystalline module with the SDM; (h) STP6$120 / 36$ polycrystalline module with the DDM. 
TABle 15: Comparison with reported results on the RTC France solar cell.

\begin{tabular}{|c|c|c|c|c|c|}
\hline Model & Algorithm & Min & Max & Mean & Std. dev. \\
\hline \multirow{24}{*}{ SDM } & $\mathrm{RF}[60]$ & $7.7301 E-04$ & NA & NA & NA \\
\hline & RSS [61] & $7.7301 E-04$ & NA & NA & NA \\
\hline & LI [62] & $1.0548 E-03$ & NA & NA & NA \\
\hline & TSLLS [63] & $7.7301 E-04$ & NA & NA & NA \\
\hline & Tong and Pora [49] & $1.5051 E-03$ & NA & NA & NA \\
\hline & Tayyan [64] & $2.9117 E-03$ & NA & NA & NA \\
\hline & MABC [65] & $9.862 E-04$ & NA & NA & NA \\
\hline & ABSO [66] & $9.9124 E-04$ & NA & NA & NA \\
\hline & BBO-M [67] & $9.8634 E-04$ & NA & NA & NA \\
\hline & GGHS [68] & $9.9078 E-04$ & NA & NA & NA \\
\hline & CARO [69] & $9.8665 E-04$ & NA & NA & NA \\
\hline & SOS [24] & $9.8609 E-04$ & $1.1982 E-03$ & $1.0245 E-03$ & $5.2184 E-05$ \\
\hline & MSSO [70] & $9.8607 E-04$ & NA & NA & NA \\
\hline & CWOA [21] & $9.8604 E-04$ & NA & NA & $1.0216 E-08$ \\
\hline & CSO [71] & $9.8602 E-04$ & NA & $9.8602 E-04$ & $5.4941 E-09$ \\
\hline & MADE [72] & $9.8602 E-04$ & $9.8602 E-04$ & $9.8602 E-04$ & $2.74 E-15$ \\
\hline & EO-Jaya [73] & $9.8603 E-04$ & NA & NA & NA \\
\hline & ILCOA [74] & $9.8602 E-04$ & NA & NA & NA \\
\hline & FPSO [75] & $9.8602 E-04$ & NA & NA & $2.0142 E-08$ \\
\hline & PGJAYA [76] & $9.8602 E-04$ & $9.8602 E-04$ & $9.8602 E-04$ & $1.4485 E-09$ \\
\hline & OBWOA [77] & $9.8602 E-04$ & NA & NA & NA \\
\hline & ABC-TRR [78] & $9.8602 E-04$ & $9.8602 E-04$ & $9.8602 E-04$ & $6.15 E-17$ \\
\hline & NM-MPSO [79] & $9.8602 E-04$ & NA & NA & NA \\
\hline & $\mathrm{SDO}$ & $9.8602 E-04$ & $9.8616 E-04$ & $9.8603 E-04$ & $2.5141 E-08$ \\
\hline \multirow{19}{*}{ DDM } & MABC [65] & $9.8276 E-04$ & NA & NA & NA \\
\hline & ABSO [66] & $9.8344 E-04$ & NA & NA & NA \\
\hline & BBO-M [67] & $9.8272 E-04$ & NA & NA & NA \\
\hline & IGHS [68] & $9.8635 E-04$ & NA & NA & NA \\
\hline & CARO [69] & $9.8260 E-04$ & NA & NA & NA \\
\hline & SOS [24] & $9.8518 E-04$ & $1.3498 E-03$ & $1.0627 E-03$ & $9.6141 E-05$ \\
\hline & MSSO [70] & $9.8281 E-04$ & NA & NA & NA \\
\hline & CWOA [21] & $9.8279 E-04$ & NA & NA & $1.1333 E-07$ \\
\hline & CSO [71] & $9.8252 E-04$ & NA & $9.9619 E-04$ & $3.4681 E-05$ \\
\hline & MADE [72] & $9.8261 E-04$ & $9.8786 E-04$ & $9.8608 E-04$ & $8.02 E-05$ \\
\hline & EO-Jaya [73] & $9.8262 E-04$ & NA & NA & NA \\
\hline & ILCOA [74] & $9.8257 E-04$ & NA & NA & NA \\
\hline & FPSO [75] & $9.8253 E-04$ & NA & NA & $3.1469 E-08$ \\
\hline & PGJAYA [76] & $9.8263 E-04$ & $9.9499 E-04$ & $9.8582 E-04$ & $2.5375 E-05$ \\
\hline & OBWOA [77] & $9.8251 E-04$ & NA & NA & NA \\
\hline & ABC-TRR [78] & $9.8249 E-04$ & $9.8602 E-03$ & $9.8256 E-03$ & $4.95 E-07$ \\
\hline & NM-MPSO [79] & $9.8250 E-04$ & NA & NA & NA \\
\hline & EVPS [80] & $9.8510 E-04$ & $1.1190 E-03$ & $1.0083 E-03$ & $2.5375 E-05$ \\
\hline & SDO & $9.8250 E-04$ & $1.0271 E-03$ & $9.8822 E-04$ & $8.8518 E-06$ \\
\hline
\end{tabular}

NA: not available in the literature.

it is with the capability of jumping out of local optima and exploring more promising regions.

(iii) The population size affects the performance of SDO significantly. In general, a small size is relatively safe for low-dimensional optimization problems. For the problem considered in this work, the size setting as 20 is recommended for SDO.

The experimental results and comparisons demonstrate that SDO can serve as a promising alternative to extract accurate and reliable parameters for PV models. In future work, on one hand, local search methods and adaptive learning strategies will be employed to accelerate SDO's convergence rate especially at the early stage and to choose appropriate population sizes for SDO in solving different optimization problems, respectively. On the other hand, attempts will be made to apply SDO to other electrical engineering problems such as MPPT, economic dispatch, and optimal power flow.

\section{Nomenclature}
$I_{\mathrm{d}}: \quad$ Diode current $(\mathrm{A})$
$I_{\mathrm{L}}: \quad$ Output current (A)
$I_{\mathrm{ph}}$ : $\quad$ Photogenerated current (A)
$I_{\mathrm{sd}}, I_{\mathrm{sd} 1}$, and Saturation currents (A)
$I_{\mathrm{sd} 2}$ :
$I_{\text {sh }}$ : $\quad$ Shunt resistor current (A)
$k$ : $\quad$ Boltzmann constant
$n, n_{1}$, and $n_{2}$ : Diode ideality factors
$N_{\mathrm{p}}$ : $\quad$ Number of cells in parallel 


\begin{tabular}{|c|c|}
\hline$N_{\mathrm{s}}:$ & Number of cells in series \\
\hline$q:$ & Electron charge \\
\hline$R_{\mathrm{s}}:$ & Series resistance $(\Omega)$ \\
\hline$R_{\mathrm{sh}}:$ & Shunt resistance $(\Omega)$ \\
\hline$T:$ & Cell temperature $(\mathrm{K})$ \\
\hline$V_{\mathrm{L}}:$ & Output voltage (V) \\
\hline$V_{\mathrm{t}}:$ & Diode thermal voltage $(\mathrm{V})$ \\
\hline $\mathrm{I}-\mathrm{V} \dot{\mathrm{I}}$ & Current-voltage \\
\hline & Power-voltage \\
\hline PV: & Photovoltaic \\
\hline$N:$ & Number of experimental data \\
\hline$x:$ & Extracted parameters vector \\
\hline SDM: & Single diode model \\
\hline DDM: & Double diode model \\
\hline IAE: & Individual absolute error \\
\hline RMSE: & Root mean square error \\
\hline Min: & Minimum RMSE \\
\hline Max: & Maximum RMSE \\
\hline Mean: & Mean RMSE \\
\hline Std. Dev: & Standard deviation \\
\hline$D:$ & Dimension of extracted parameters vector \\
\hline ps: & Size of population \\
\hline$t:$ & Current iteration \\
\hline$t_{\max }:$ & Maximum number of iterations \\
\hline Max_FEs: & Maximum number of fitness evaluations \\
\hline $\mathbf{E}_{\mathrm{e}}:$ & Equilibrium point \\
\hline $\mathbf{P}_{\mathrm{i}}:$ & $i$ th price solution \\
\hline $\mathbf{P}_{\text {best }}:$ & Best price solution found so far \\
\hline $\mathbf{Q}_{\mathrm{i}}:$ & $i$ th quantity solution \\
\hline $\mathbf{T P}_{\mathrm{i}}:$ & ith trial price solution \\
\hline $\mathrm{TQ}_{\mathrm{i}}$ & $i$ th trial quantity solution \\
\hline Kg: & Supply slop \\
\hline $\mathbf{K}_{\mathrm{f}}:$ & Demand slop \\
\hline$\alpha:$ & Supply weight \\
\hline$\beta:$ & Demand weight \\
\hline $\begin{array}{l}r_{1}, r_{2}, r_{3} \\
\text { and } r_{4}:\end{array}$ & Random real numbers in $(0,1)$ \\
\hline ABSO: & Artificial bee swarm optimization \\
\hline ABC-TRR: & Hybrid trust-region reflective algorithm \\
\hline BBO-M: & $\begin{array}{l}\text { Biogeography-based optimization with } \\
\text { mutation strategies }\end{array}$ \\
\hline CARO: & Chaotic asexual reproduction optimization \\
\hline CLPSO: & $\begin{array}{l}\text { Comprehensive learning particle swarm } \\
\text { optimizer }\end{array}$ \\
\hline CSO: & Cat swarm optimization \\
\hline CWOA: & $\begin{array}{l}\text { Improved chaotic whale optimization } \\
\text { algorithm }\end{array}$ \\
\hline DE/BBO: & $\begin{array}{l}\text { Hybrid differential evolution with } \\
\text { biogeography-based optimization }\end{array}$ \\
\hline EO-Jaya: & Elite opposition-based Jaya algorithm \\
\hline EVPS: & Enhanced vibrating particles system \\
\hline FPSO: & Flexible particle swarm optimization \\
\hline GGHS: & Grouping-based global harmony search \\
\hline GOTLBO: & $\begin{array}{l}\text { Generalized oppositional teaching-learning- } \\
\text { based optimization }\end{array}$ \\
\hline IGH & Innovative global harmony search \\
\hline IJAY & Improved Jaya optimization algorithm \\
\hline
\end{tabular}

ILCOA: Improved Lozi map-based chaotic optimization

IWOA: Improved whale optimization algorithm

LETLBO: Teaching-learning-based optimization with learning experience of other learners

LI: $\quad$ Linear identification method

MABC: $\quad$ Modified artificial bee colony algorithm

MADE: $\quad$ Memetic adaptive differential evolution

MSSO: $\quad$ Modified simplified swarm optimization

NM-MPSO: Hybrid nelder-mead and modified particle swarm optimization

OBWOA: Improved opposition-based whale optimization algorithm

ODE: Opposition-based differential evolution

PGJAYA: Performance-guided Jaya algorithm

RF:

SATLBO: Self-adaptive teaching-learning-based

optimization

Supply-demand-based optimization

SOS: $\quad$ Symbiotic organisms search

Tayyan: Tayyan's method

TLABC: $\quad$ Teaching-learning-based artificial bee colony

Tong and Tong and Pora's method

Pora:

TSLLS: $\quad$ Two-step linear least-squares method.

\section{Data Availability}

The data used to support the findings of this study are available from the corresponding author upon request.

\section{Conflicts of Interest}

The authors declare that they have no conflicts of interest.

\section{Acknowledgments}

The authors would like to thank Dr. Weiguo Zhao for providing the original code of SDO. This work was supported by the National Natural Science Foundation of China (Grant nos. 51907035, 51867005, and 51667007), the Scientific Research Foundation for the Introduction of Talent of Guizhou University (Grant no. [2017]16), the Guizhou Province Science and Technology Innovation Talent Team Project (Grant no. [2018]5615), the Guizhou Education Department Growth Foundation for Youth Scientific and Technological Talents (Grant no. QianJiaoHe KY Zi [2018] 108), and the Science and Technology Foundation of Guizhou Province (Grant no. QianKeHe Platform Talents [2018]5781).

\section{References}

[1] M. H. Rehmani, M. Reisslein, A. Rachedi, M. Erol-Kantarci, and M. Radenkovic, "Integrating renewable energy resources into the smart grid: recent developments in information and 
communication technologies," IEEE Transactions on Industrial Informatics, vol. 14, no. 7, pp. 2814-2825, 2018.

[2] N. A. Ludin, N. I. Mustafa, M. M. Hanafiah et al., "Prospects of life cycle assessment of renewable energy from solar photovoltaic technologies: a review," Renewable and Sustainable Energy Reviews, vol. 96, pp. 11-28, 2018.

[3] P. Li, W. Gu, L. Wang, B. Xu, M. Wu, and W. Shen, "Dynamic equivalent modeling of two-staged photovoltaic power station clusters based on dynamic affinity propagation clustering algorithm," International Journal of Electrical Power \& Energy Systems, vol. 95, pp. 463-475, 2018.

[4] International Energy Agency, Renewables 2018, International Energy Agency, Paris, France, 2018.

[5] A. M. Humada, M. Hojabri, S. Mekhilef, and H. M. Hamada, "Solar cell parameters extraction based on single and doublediode models: a review," Renewable and Sustainable Energy Reviews, vol. 56, pp. 494-509, 2016.

[6] R. C. M. Gomes, M. A. Vitorino, D. A. Fernandes, and R. Wang, "Shuffled complex evolution on photovoltaic parameter extraction: a comparative analysis," IEEE Transactions on Sustainable Energy, vol. 8, no. 2, pp. 805-815, 2016.

[7] W. Li, M. C. Paul, M. Rolley et al., "A scaling law for monocrystalline PV/T modules with CCPC and comparison with triple junction PV cells," Applied Energy, vol. 202, pp. 755-771, 2017.

[8] S. Raj, A. Kumar Sinha, and A. K. Panchal, "Solar cell parameters estimation from illuminated I-V characteristic using linear slope equations and Newton-Raphson technique," Journal of Renewable and Sustainable Energy, vol. 5, no. 3, Article ID 033105, 2013.

[9] M. G. Villalva, J. R. Gazoli, and E. R. Filho, "Comprehensive approach to modeling and simulation of photovoltaic arrays," IEEE Transactions on Power Electronics, vol. 24, no. 5, pp. 1198-1208, 2009.

[10] Y. Xu, X. Kong, Y. Zeng, S. Tao, and X. Xiao, "A modeling method for photovoltaic cells using explicit equations and optimization algorithm," International Journal of Electrical Power \& Energy Systems, vol. 59, pp. 23-28, 2014.

[11] G. Xiong, D. Shi, and X. Duan, "Multi-strategy ensemble biogeography-based optimization for economic dispatch problems," Applied Energy, vol. 111, pp. 801-811, 2013.

[12] G. Xiong, J. Zhang, D. Shi, and Y. He, "Parameter identification of solid oxide fuel cells with ranking teaching-learning based algorithm," Energy Conversion and Management, vol. 174, pp. 126-137, 2018.

[13] G. Xiong, D. Shi, J. Zhang, and Y. Zhang, "A binary coded brain storm optimization for fault section diagnosis of power systems," Electric Power Systems Research, vol. 163, pp. 441451, 2018.

[14] M. S. Ismail, M. Moghavvemi, and T. M. I. Mahlia, "Characterization of PV panel and global optimization of its model parameters using genetic algorithm," Energy Conversion and Management, vol. 73, pp. 10-25, 2013.

[15] C. Chellaswamy and R. Ramesh, "Parameter extraction of solar cell models based on adaptive differential evolution algorithm," Renewable Energy, vol. 97, pp. 823-837, 2016.

[16] P. P. Biswas, P. N. Suganthan, G. Wu, and G. A. J. Amaratunga, "Parameter estimation of solar cells using datasheet information with the application of an adaptive differential evolution algorithm," Renewable Energy, vol. 132, pp. 425-438, 2019.

[17] A. R. Jordehi, "Enhanced leader particle swarm optimisation (ELPSO): an efficient algorithm for parameter estimation of photovoltaic (PV) cells and modules," Solar Energy, vol. 159, pp. 78-87, 2018.

[18] M. Merchaoui, A. Sakly, and M. F. Mimouni, "Particle swarm optimisation with adaptive mutation strategy for photovoltaic solar cell/module parameter extraction," Energy Conversion and Management, vol. 175, pp. 151-163, 2018.

[19] A. Askarzadeh and L. D. S. Coelho, "Determination of photovoltaic modules parameters at different operating conditions using a novel bird mating optimizer approach," Energy Conversion and Management, vol. 89, pp. 608-614, 2015.

[20] E. E. Ali, M. A. El-Hameed, A. A. El-Fergany, and M. M. ElArini, "Parameter extraction of photovoltaic generating units using multi-verse optimizer," Sustainable Energy Technologies and Assessments, vol. 17, pp. 68-76, 2016.

[21] D. Oliva, M. Abd El Aziz, and A. Ella Hassanien, "Parameter estimation of photovoltaic cells using an improved chaotic whale optimization algorithm," Applied Energy, vol. 200, pp. 141-154, 2017.

[22] X. Chen, K. Yu, W. Du, W. Zhao, and G. Liu, "Parameters identification of solar cell models using generalized oppositional teaching learning based optimization," Energy, vol. 99, pp. 170-180, 2016.

[23] K. Yu, J. J. Liang, B. Y. Qu, X. Chen, and H. Wang, "Parameters identification of photovoltaic models using an improved JAYA optimization algorithm," Energy Conversion and Management, vol. 150, pp. 742-753, 2017.

[24] G. Xiong, J. Zhang, X. Yuan, D. Shi, and Y. He, “Application of symbiotic organisms search algorithm for parameter extraction of solar cell models," Applied Sciences, vol. 8, no. 11, p. $2155,2018$.

[25] G. Xiong, J. Zhang, D. Shi, and Y. He, "Parameter extraction of solar photovoltaic models using an improved whale optimization algorithm," Energy Conversion and Management, vol. 174, pp. 388-405, 2018.

[26] G. Xiong, J. Zhang, X. Yuan, D. Shi, Y. He, and G. Yao, "Parameter extraction of solar photovoltaic models by means of a hybrid differential evolution with whale optimization algorithm," Solar Energy, vol. 176, pp. 742-761, 2018.

[27] R. Abbassi, A. Abbassi, A. A. Heidari, and S. Mirjalili, "An efficient salp swarm-inspired algorithm for parameters identification of photovoltaic cell models," Energy Conversion and Management, vol. 179, pp. 362-372, 2019.

[28] H. G. G. Nunes, J. A. N. Pombo, P. M. R. Bento, S. J. P. S. Mariano, and M. R. A. Calado, "Collaborative swarm intelligence to estimate PV parameters," Energy Conversion and Management, vol. 185, pp. 866-890, 2019.

[29] B. Subudhi and R. Pradhan, "Bacterial foraging optimization approach to parameter extraction of a photovoltaic module," IEEE Transactions on Sustainable Energy, vol. 9, no. 1, pp. 381-389, 2018.

[30] S. Li, W. Gong, X. Yan et al., "Parameter extraction of photovoltaic models using an improved teaching-learningbased optimization," Energy Conversion and Management, vol. 186, pp. 293-305, 2019.

[31] X. Gao, Y. Cui, J. Hu et al., "Parameter extraction of solar cell models using improved shuffled complex evolution algorithm," Energy Conversion and Management, vol. 157, pp. 460-479, 2018.

[32] A. Valdivia-González, D. Zaldívar, E. Cuevas, M. PérezCisneros, F. Fausto, and A. González, “A chaos-embedded gravitational search algorithm for the identification of electrical parameters of photovoltaic cells," Energies, vol. 1052, 2017. 
[33] J. P. Ram, T. S. Babu, T. Dragicevic, and N. Rajasekar, "A new hybrid bee pollinator flower pollination algorithm for solar PV parameter estimation," Energy Conversion and Management, vol. 135, pp. 463-476, 2017.

[34] H. Rezk and A. Fathy, "A novel optimal parameters identification of triple-junction solar cell based on a recently metaheuristic water cycle algorithm," Solar Energy, vol. 157, pp. 778-791, 2017.

[35] S. Bana and R. P. Saini, "Identification of unknown parameters of a single diode photovoltaic model using particle swarm optimization with binary constraints," Renewable Energy, vol. 101, pp. 1299-1310, 2017.

[36] A. Fathy and H. Rezk, "Parameter estimation of photovoltaic system using imperialist competitive algorithm," Renewable Energy, vol. 111, pp. 307-320, 2017.

[37] D. Kler, P. Sharma, A. Banerjee, K. P. S. Rana, and V. Kumar, "PV cell and module efficient parameters estimation using evaporation rate based water cycle algorithm," Swarm and Evolutionary Computation, vol. 35, pp. 93-110, 2017.

[38] D. H. Muhsen, A. B. Ghazali, T. Khatib, and I. A. Abed, “A comparative study of evolutionary algorithms and adapting control parameters for estimating the parameters of a singlediode photovoltaic module's model," Renewable Energy, vol. 96, pp. 377-389, 2016.

[39] K. Ishaque, Z. Salam, S. Mekhilef, and A. Shamsudin, "Parameter extraction of solar photovoltaic modules using penalty-based differential evolution," Applied Energy, vol. 99, pp. 297-308, 2012.

[40] V. J. Chin, Z. Salam, and K. Ishaque, "An accurate and fast computational algorithm for the two-diode model of PV module based on a hybrid method," IEEE Transactions on Industrial Electronics, vol. 64, no. 8, pp. 6212-6222, 2017.

[41] D. H. Wolpert and W. G. Macready, "No free lunch theorems for optimization," IEEE Transactions on Evolutionary Computation, vol. 1, no. 1, pp. 67-82, 1997.

[42] W. Zhao, L. Wang, and Z. Zhang, "Supply-demand-based optimization: a novel economics-inspired algorithm for global optimization,” IEEE Access, vol. 7, pp. 73182-73206, 2019.

[43] F. V. Waugh, "Cobweb models," American Journal of Agricultural Economics, vol. 46, no. 5, pp. 732-750, 1964.

[44] C. Chiarella, "The cobweb model," Economic Modelling, vol. 5, no. 4, pp. 377-384, 1988.

[45] A. Ashouri-Zadeh, M. Toulabi, A. S. Dobakhshari, S. Taghipour-Broujeni, and A. M. Ranjbar, "A novel technique to extract the maximum power of photovoltaic array in partial shading conditions," International Journal of Electrical Power \& Energy Systems, vol. 101, pp. 500-512, 2018.

[46] V. J. Chin, Z. Salam, and K. Ishaque, "Cell modelling and model parameters estimation techniques for photovoltaic simulator application: a review," Applied Energy, vol. 154, pp. 500-519, 2015.

[47] R. Gammoudi, H. Brahmi, and R. Dhifaoui, "Estimation of climatic parameters of a PV system based on gradient method," Complexity, vol. 2019, Article ID 7385927, 10 pages, 2019.

[48] T. Easwarakhanthan, J. Bottin, I. Bouhouch, and C. Boutrit, "Nonlinear minimization algorithm for determining the solar cell parameters with microcomputers," International Journal of Solar Energy, vol. 4, no. 1, pp. 1-12, 1986.

[49] N. T. Tong and W. Pora, "A parameter extraction technique exploiting intrinsic properties of solar cells," Applied Energy, vol. 176, pp. 104-115, 2016.

[50] J. J. Liang, A. K. Qin, P. N. Suganthan, and S. Baskar, "Comprehensive learning particle swarm optimizer for global optimization of multimodal functions," IEEE Transactions on Evolutionary Computation, vol. 10, no. 3, pp. 281-295, 2006.

[51] W. Gong, Z. Cai, and C. X. Ling, "DE/BBO: a hybrid differential evolution with biogeography-based optimization for global numerical optimization," Soft Computing, vol. 15, no. 4, pp. 645-665, 2010.

[52] F. Zou, L. Wang, X. Hei, and D. Chen, "Teaching-learningbased optimization with learning experience of other learners and its application," Applied Soft Computing, vol. 37, pp. 725-736, 2015.

[53] W.-F. Gao and S.-Y. Liu, "A modified artificial bee colony algorithm," Computers \& Operations Research, vol. 39, no. 3, pp. 687-697, 2012.

[54] S. Rahnamayan, H. R. Tizhoosh, and M. M. A. Salama, "Opposition-based differential evolution," IEEE Transactions on Evolutionary Computation, vol. 12, no. 1, pp. 64-79, 2008.

[55] X. Chen, B. Xu, C. Mei, Y. Ding, and K. Li, "Teachinglearning-based artificial bee colony for solar photovoltaic parameter estimation," Applied Energy, vol. 212, pp. 1578$1588,2018$.

[56] K. Yu, X. Chen, X. Wang, and Z. Wang, "Parameters identification of photovoltaic models using self-adaptive teachinglearning-based optimization," Energy Conversion and Management, vol. 145, pp. 233-246, 2017.

[57] S. García, D. Molina, M. Lozano, and F. Herrera, "A study on the use of non-parametric tests for analyzing the evolutionary algorithms' behaviour: a case study on the CEC'2005 special session on real parameter optimization," Journal of Heuristics, vol. 15, no. 6, pp. 617-644, 2009.

[58] G. Xiong, J. Zhang, X. Yuan et al., "A novel method for economic dispatch with across neighborhood search: a case study in a provincial power grid, China," Complexity, vol. 2018, Article ID 2591341, 18 pages, 2018.

[59] G. Xiong and D. Shi, "Hybrid biogeography-based optimization with brain storm optimization for non-convex dynamic economic dispatch with valve-point effects," Energy, vol. 157, pp. 424-435, 2018.

[60] A. Laudani, F. Riganti Fulginei, and A. Salvini, "High performing extraction procedure for the one-diode model of a photovoltaic panel from experimental I-V curves by using reduced forms," Solar Energy, vol. 103, no. 103, pp. 316-326, 2014.

[61] A. A. Cardenas, M. Carrasco, F. Mancilla-David, A. Street, and R. Cardenas, "Experimental parameter extraction in the single-diode photovoltaic model via a reduced-space search," IEEE Transactions on Industrial Electronics, vol. 64, no. 2, pp. 1468-1476, 2017.

[62] H. I. L. Li, Z. Ye, J. Ye, D. Yang, and H. Du, "A linear identification of diode models from single I-V characteristics of PV panels," IEEE Transactions on Industrial Electronics, vol. 62, no. 7, pp. 4181-4193, 2015.

[63] F. J. Toledo, J. M. Blanes, and V. Galiano, "Two-step linear least-squares method for photovoltaic single-diode model parameters extraction," IEEE Transactions on Industrial Electronics, vol. 65, no. 8, pp. 6301-6308, 2018.

[64] A. A. E. Tayyan, "An approach to extract the parameters of solar cells from their illuminated I-V curves using the Lambert W function," Sudan University of Science \& Technology, vol. 39, pp. 1-15, 2015.

[65] M. Jamadi, F. Merrikh-Bayat, and M. Bigdeli, "Very accurate parameter estimation of single- and double-diode solar cell models using a modified artificial bee colony algorithm," International Journal of Energy and Environmental Engineering, vol. 7, no. 1, pp. 13-25, 2016. 
[66] A. Askarzadeh and A. Rezazadeh, "Artificial bee swarm optimization algorithm for parameters identification of solar cell models," Applied Energy, vol. 102, no. 2, pp. 943-949, 2013.

[67] Q. Niu, L. Zhang, and K. Li, "A biogeography-based optimization algorithm with mutation strategies for model parameter estimation of solar and fuel cells," Energy Conversion and Management, vol. 86, pp. 1173-1185, 2014.

[68] A. Askarzadeh and A. Rezazadeh, "Parameter identification for solar cell models using harmony search-based algorithms," Solar Energy, vol. 86, no. 11, pp. 3241-3249, 2012.

[69] X. Yuan, Y. He, and L. Liu, "Parameter extraction of solar cell models using chaotic asexual reproduction optimization," Neural Computing and Applications, vol. 26, no. 5, pp. 1227-1239, 2015.

[70] P. Lin, S. Cheng, W. Yeh, Z. Chen, and L. Wu, "Parameters extraction of solar cell models using a modified simplified swarm optimization algorithm," Solar Energy, vol. 144, pp. 594-603, 2017.

[71] L. Guo, Z. Meng, Y. Sun, and L. Wang, "Parameter identification and sensitivity analysis of solar cell models with cat swarm optimization algorithm," Energy Conversion and Management, vol. 108, pp. 520-528, 2016.

[72] S. Li, W. Gong, X. Yan, C. Hu, D. Bai, and L. Wang, "Parameter estimation of photovoltaic models with memetic adaptive differential evolution," Solar Energy, vol. 190, pp. 465-474, 2019.

[73] L. Wang and C. Huang, “A novel elite opposition-based Jaya algorithm for parameter estimation of photovoltaic cell models," Optik, vol. 155, pp. 351-356, 2018.

[74] N. Pourmousa, S. M. Ebrahimi, M. Malekzadeh, and M. Alizadeh, "Parameter estimation of photovoltaic cells using improved Lozi map based chaotic optimization algorithm," Solar Energy, vol. 180, pp. 180-191, 2019.

[75] S. M. Ebrahimi, E. Salahshour, M. Malekzadeh, and F. Francisco Gordillo, "Parameters identification of PV solar cells and modules using flexible particle swarm optimization algorithm," Energy, vol. 179, pp. 358-372, 2019.

[76] K. Yu, B. Qu, C. Yue, S. Ge, X. Chen, and J. Liang, “A performance-guided JAYA algorithm for parameters identification of photovoltaic cell and module," Applied Energy, vol. 237, pp. 241-257, 2019.

[77] M. Abd Elaziz and D. Oliva, "Parameter estimation of solar cells diode models by an improved opposition-based whale optimization algorithm," Energy Conversion and Management, vol. 171, pp. 1843-1859, 2018.

[78] L. Wu, Z. Chen, C. Long et al., "Parameter extraction of photovoltaic models from measured I-V characteristics curves using a hybrid trust-region reflective algorithm," Applied Energy, vol. 232, pp. 36-53, 2018.

[79] N. F. A. Hamid, N. A. Rahim, and J. Selvaraj, "Solar cell parameters identification using hybrid Nelder-Mead and modified particle swarm optimization," Journal of Renewable and Sustainable Energy, vol. 8, no. 1, p. 015502, 2016.

[80] P. J. Gnetchejo, S. N. Essiane, P. Ele, R. Wamkeue, D. M. Wapet, and S. P. Ngoffe, "Enhanced vibrating particles system Algorithm for parameters estimation of photovoltaic system," Journal of Power and Energy Engineering, vol. 7, no. 8, pp. 1-26, 2019. 


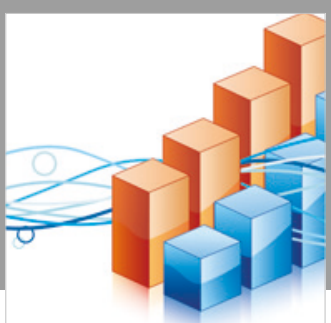

Advances in

Operations Research

\section{-n-m}
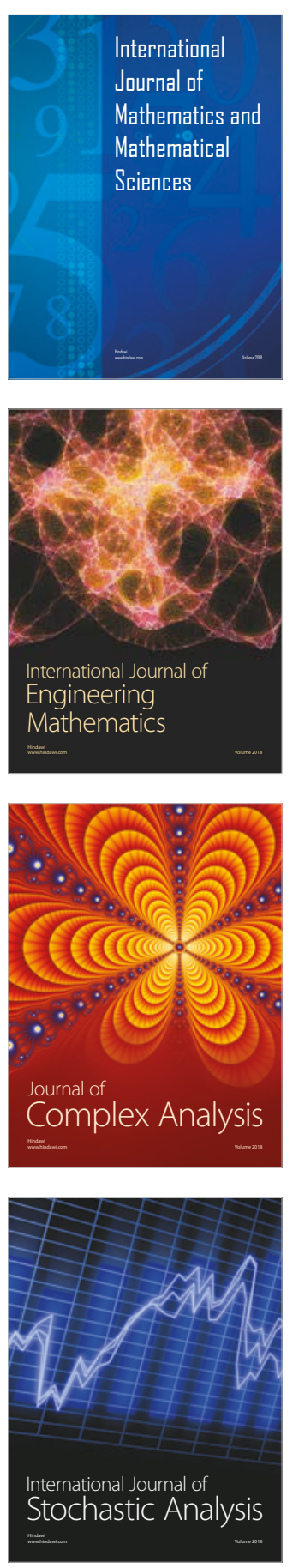
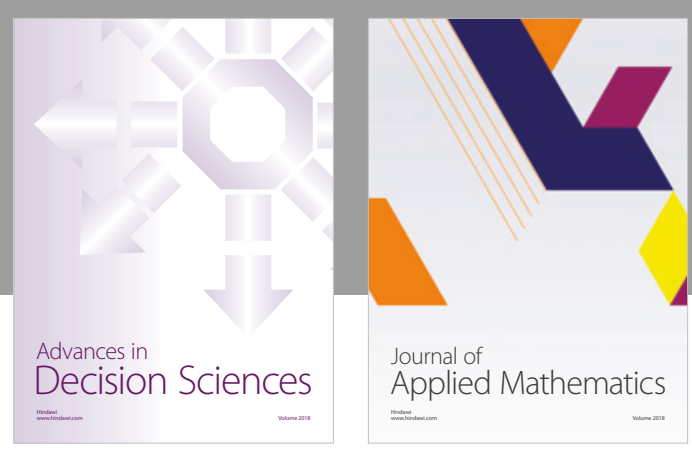

Journal of

Applied Mathematics
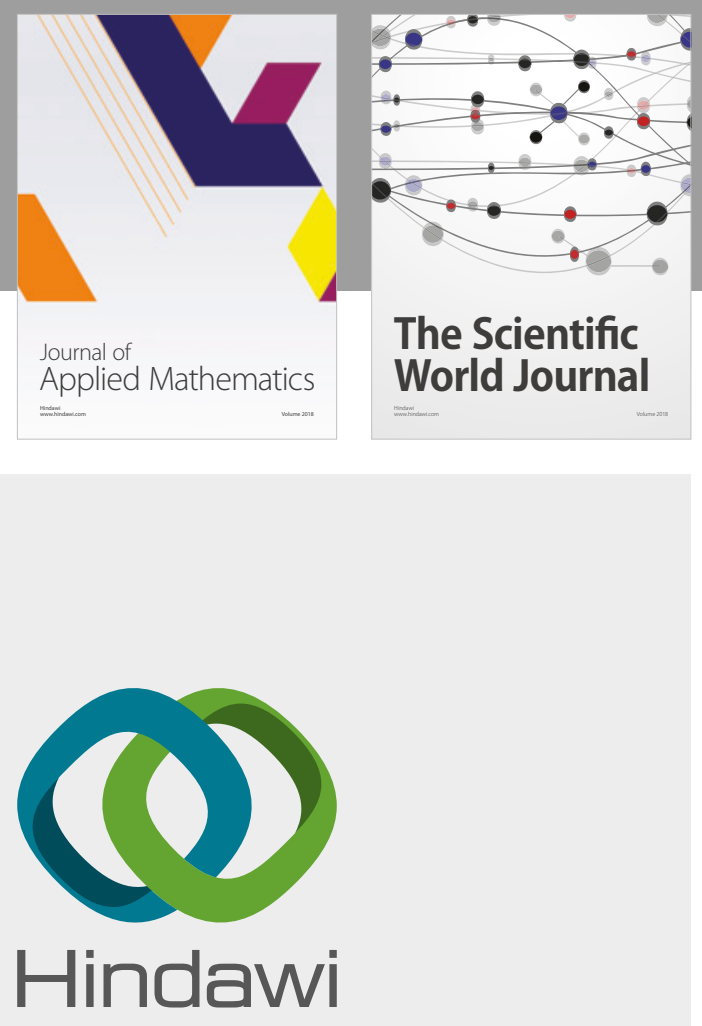

Submit your manuscripts at

www.hindawi.com

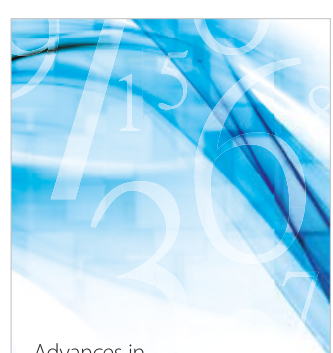

Advances in
Numerical Analysis
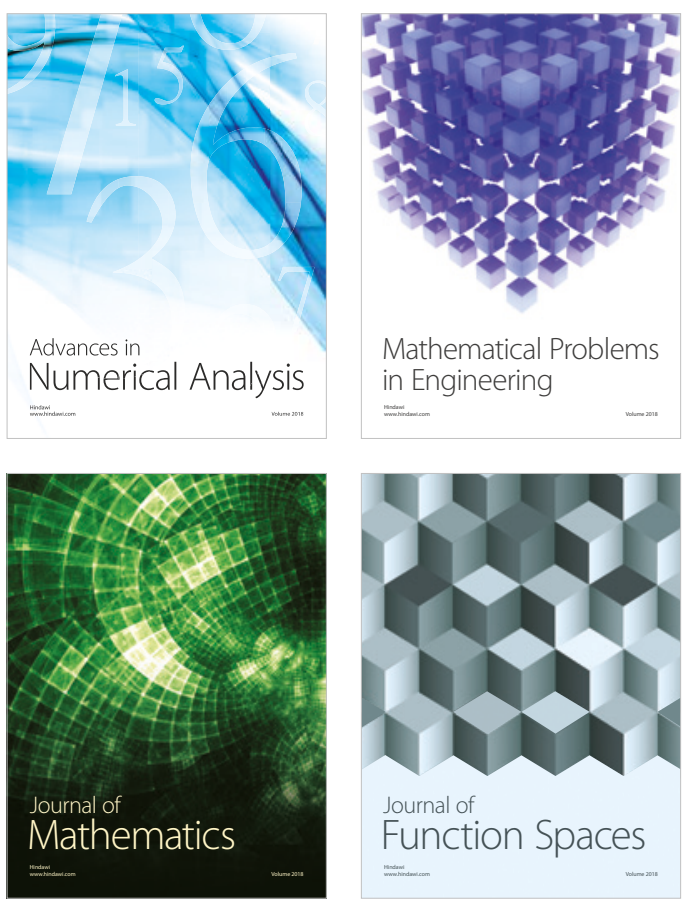

Mathematical Problems in Engineering

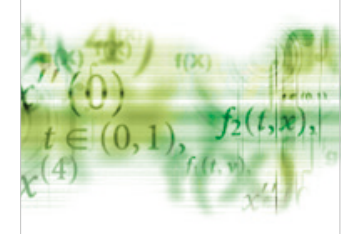

International Journal of

Differential Equations

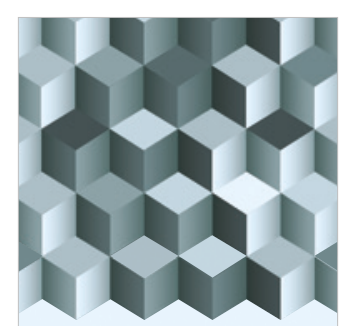

Journal of

Function Spaces
The Scientific

World Journal

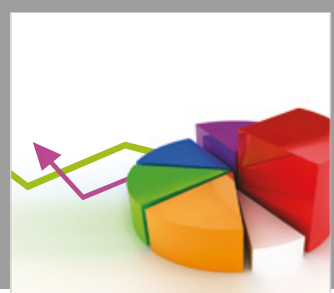

Journal of

Probability and Statistics
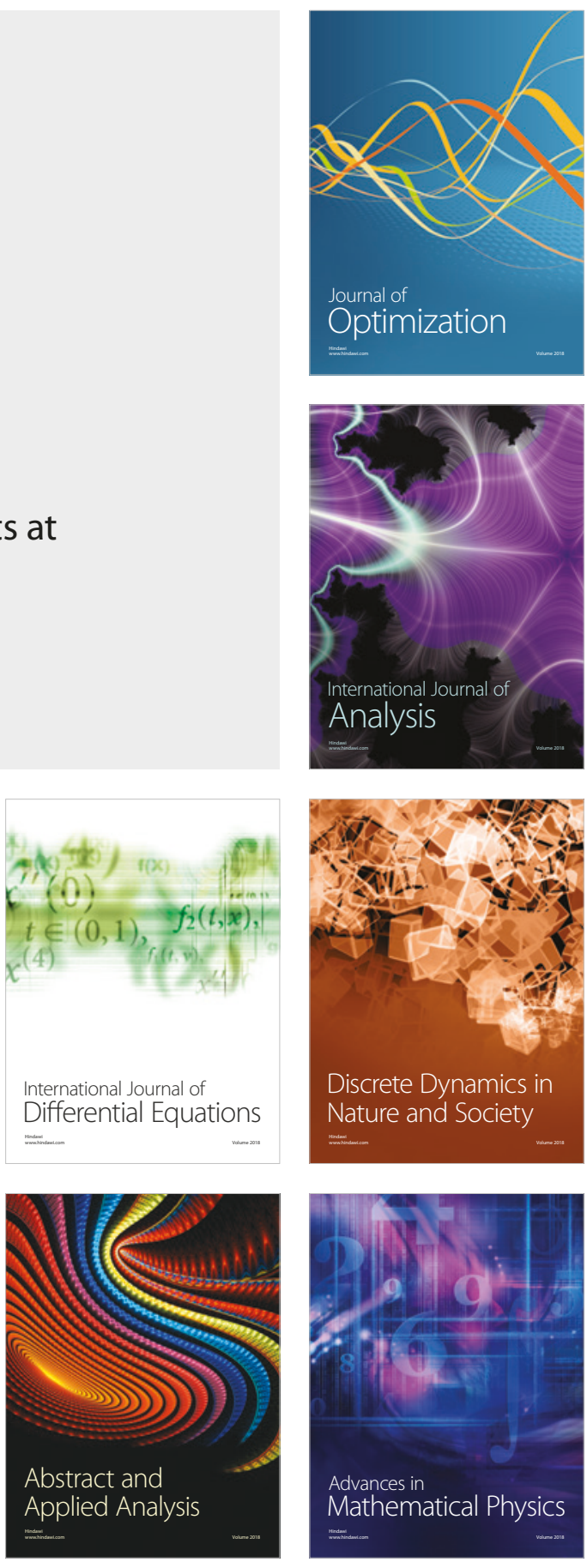